\title{
Automated Manufacturing and Processing of Fiber-Reinforced Polymer (FRP) Composites: An Additive Review of Contemporary and Modern Techniques for Advanced Materials Manufacturing Jolie Frketic $^{1}$, Tarik Dickens ${ }^{1}{ }^{*}$, Subramanian Ramakrishnan ${ }^{2}$ \\ ${ }^{1}$ High Performance Materials Institute \\ ${ }^{2}$ Department of Chemical and Biomedical Engineering \\ Florida A\&M University-Florida State University College of Engineering, 2525 Pottsdamer St., Tallahassee, FL 32310
}

\section{ABSTRACT}

High throughput automated techniques are nowadays playing a key role in polymer composite manufacturing in a number of industries such as automotive and aerospace. There is a need to produce high volume parts efficiently. Automated manufacturing methods such as automated tape layup and automated fiber placement can produce composite parts efficiently, and with the advent of additive manufacturing the complexity of these components are increasing. This paper will review contemporary composite manufacturing methods: filament winding, automated tape layup, and automated fiber placement, and the newer automation techniques of robotic pick-and-place and continuous tow shearing. It also addresses recent advances in composite additive manufacturing using vat photopolymerization, binder jetting, material extrusion, sheet lamination and powder bed fusion. Methods, materials and testing results of the manufactured components will be discussed.

Keywords: Polymer Matrix Composites (PMC) (A), Additive Manufacturing, Automation (E)

*Corresponding Author: dickens@eng.fsu.edu 


\section{INTRODUCTION}

Additive manufacturing (AM), or three dimensional (3D) printing, has received great interest in the last few years and is known for rapid prototyping. It has continued to grow and is transitioning into a reliable way of creating diverse objects such as dresses, jet engines and turbine blades [1,2]. Additive manufacturing commonly uses plastics to create parts layer by layer, but has progressed to using ceramics, paper, and even polymer matrix composites. More recently, Oak Ridge National Laboratory and Cincinnati INC. printed parts to recreate the Shelby Cobra out of carbon fiber reinforced ABS using their Big Area Additive Manufacturing (BAAM) machine. This achievement has expanded the definition of composite printing with the inclusion of reinforcing material for strengthening the filament [3-5].

Composites are used for many applications in the aerospace and automotive industry due to their high specific strength. Traditional manufacturing methods for composites are time consuming and labor intensive, which leads to high costs. For manual layups, the labor cost associated with creating composites takes a large portion of the total manufacturing cost [6]. A highly trained technician creates about $2.5 \mathrm{lbs}$. of composite material per hour, but even the best can make a mistake [7]. Human error can introduce voids and irregularities into the composite part during production, which negatively affects mechanical properties, making parts unusable for standard operation. For those reasons, manufacturers, especially in western Europe and the USA, are transitioning to automated composite manufacturing to improve process and cost efficiency [8-10]. 
Three popular mechanized composite manufacturing techniques used in industry are automated tape layup (ATL), automated fiber placement (AFP), and filament winding (FW). These processes have been heavily researched, but their use is limited by the cost of the specialized machinery and constraints in fabrication of complex parts. However, the composite strength matches that of traditional manufacturing techniques, making the processes beneficial in speeding up production and cutting labor costs. Evidence exists in the aerospace industry which has reported a 70-85\% reduction in man hours due to the implementation of automated composite tape layers [9].

Additive manufacturing is currently on the rise in industries such as the biomedical, aerospace, and engineering fields, because it offers prototyped parts quickly and inexpensively without the need for specialized tooling [11-14]. One of the drawbacks of additive manufacturing is the low strength of the polymer and weakly bonded (i.e. green ceramic) parts $[15,16]$. A way of increasing the strength is by using fillers and fiber reinforcements. Fillers have been utilized as crack bridging and toughening agents in polymer systems for some time. For example: Stratasys Inc., incorporates millimeter-sized glass whiskers in their specialty filament for material extrusion printing [17]. In another example, FiberForge Inc., a 3D printing company, created hardware to print carbon fiber filament for a 6 x 6 " build tray [18].

This review paper studies the current automated additive manufacturing techniques for composites in industry such as filament winding (FW), automated tape layup (ATL), automated fiber placement (AFP), as well as the newer lab-scale automation techniques of robotic pick and place and continuous tow shearing (CTS) $[6,19,20]$. Also discussed is additive manufacturing technology such as vat photopolymerization, binder jetting, 
material extrusion, sheet lamination, and powder bed fusion of fiber reinforced polymer parts $[15,21-25]$.

\section{AUTOMATION OF COMPOSITE MANUFACTURING}

Automation is the mechanization of work to reduce human-machine interaction [26]. Historically, the Industrial Revolution introduced ideas of standardization and value-added processing to meet increasing production volumes. The metalwork of the twentieth century has given rise to ever-increasing proficiency of polymer-based reinforced composites in the twenty-first century. If composites could be manufactured as easily as metal parts, then polymer composite materials stand to replace traditional materials in various applications where environmental, structural and weight are significant concerns.

Though there are many methods to create composites, not all are suited for high volume output automation. For example, hand layups are useful for making small numbers of specialty parts, and the automation of which would not be cost effective. Injection molding is good for a large number of parts, but customization of the parts is costly due to the need for dedicated molds. The optimum production capacity for composite manufacturing methods given the increasing level of automation as seen in Figure 1 [8]. 


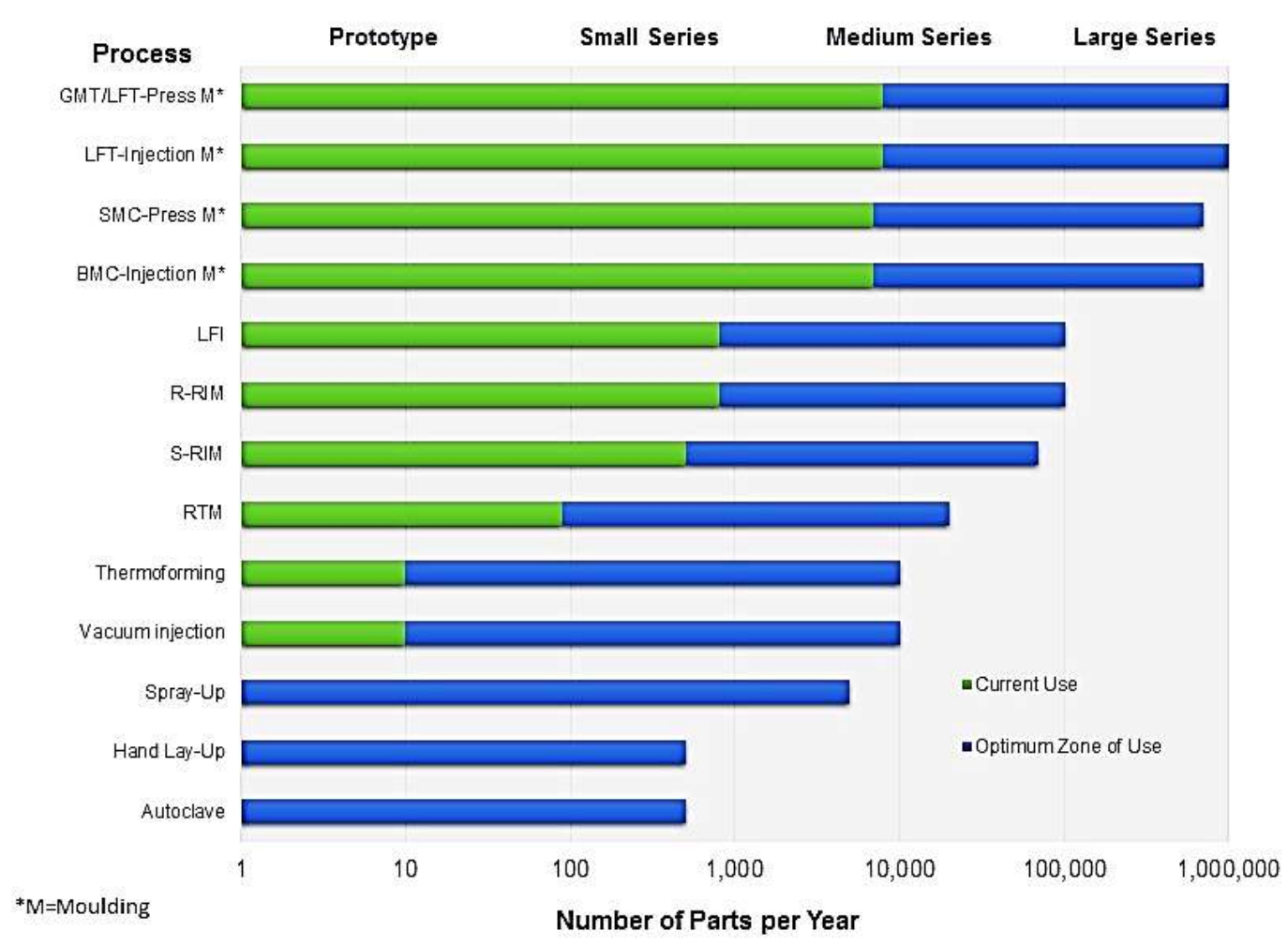

Figure 1: Ranking of composite part manufacturing processes by optimum output [8]

The ability to quickly and precisely manufacture metal parts comes from the ability to use computer numerically controlled (CNC) machines for subtractive manufacturing methods. The manufacturing of composites lends itself to additive manufacturing because of the use of polymers, which are easily shaped through a variety of processing steps. Lowlevel additive manufacturing techniques such as ATL, AFP, and FW use a computer-aided design and/ or computer-aided manufacturing model to build up a part, in a layer by layer process, which is the basis for the additive manufacturing that is known today [27]. As a result, AFP, ATL and FW have become the industrial benchmarks newly developed additive processes for composites are evaluated against. In summary, these high output methods are considered additive in nature because of their use of a layer wise process, where material is deposited in a layer-wise fashion using CNC machines. 


\subsection{Industrial automation}

Currently, the methods closest to additive manufacturing in industrial composite production are ATL, AFP, and FW. These make use of laminated tapes or smaller laminated tows to create a part. ATL and AFP are CNC machines with programmable axis movements, axis drives, and delivery heads that meticulously place composite tapes and tows to fabricate a specific part structure [28]. All of these processes make use of resinimpregnated continuous fibers, also known as prepregs [7].

\subsubsection{Filament winding (FW)}

FW is an automatic method to create axisymmetric as well as some non-axisymmetric parts (i.e. pipe bends) by winding continuous prepreg sheets, rovings, and monofilaments around a rotating mandrel before curing [10]. For non-axisymmetric parts, 6 or 7 axis machines, like those manufactured by CNC Technics, are necessary [29-31]. Filament winding may use either dry fibers passed through a resin bath (wet winding) and prepreg materials (dry winding) for production [30]. The basic process of filament winding is displayed in Figure 2. The first step in wet winding is gathering fibers from a series of creels, grouping the fibers by passing them through a textile board or comb, and pulling the grouped fibers through a resin bath. The resin bath contains liquid resin and catalyst, but may include additional ingredients such as pigments or UV absorbers [32]. Upon exiting the resin bath, the rovings are pulled through a wiper system, such as squeeze rollers, which controls the amount of resin on the fibers. Fiber guides keep consistent tension on the fibers during the process. Once the rovings are impregnated, they pass through a comb, straight bar, or ring and become a flat band of fibers. At this point, the flat band (or prepreg material for dry winding) is positioned onto the mandrel, and a carriage system travels back 
and forth to wind the fibers around the mandrel while the mandrel spins. The speeds of the carriage and the mandrel are adjusted to match the desired winding pattern for the part. Several different winding patterns such as hoop, helical, and polar winding can be formed this way. In $\mathrm{CNC} \mathrm{FW}$, the mandrel and carriage are able to move independently of each other, allowing for infinite winding possibilities; this allows production of complex shapes with no axis of symmetry, such as helicopter blades [32].
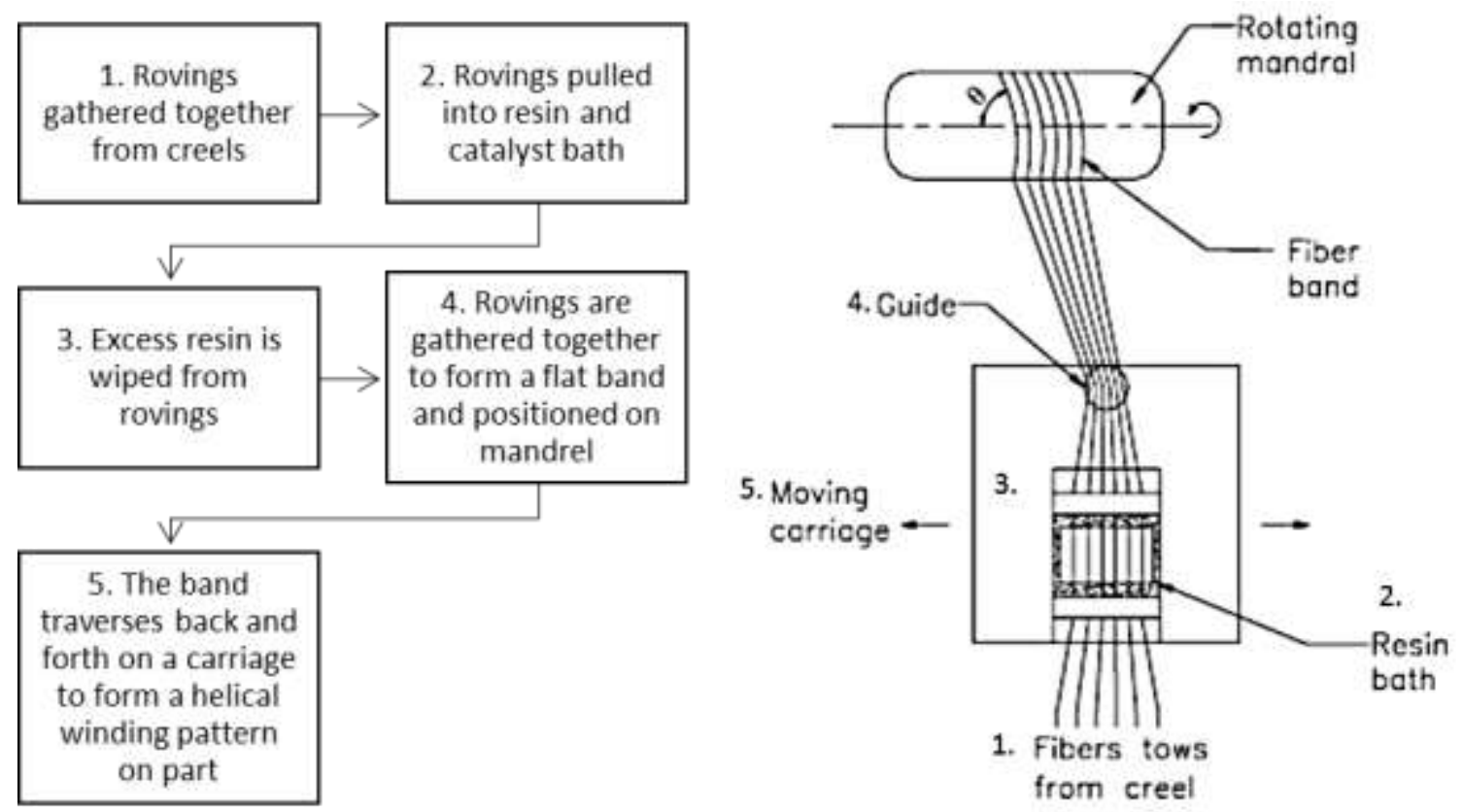

Figure 2: Filament winding flow chart and diagram [30]

After the desired thickness of the composite part has been reached, the mandrel is cured. After curing, the mandrel can be removed from the part. FW can be used for parts such as large pressure vessels, as well as parts as small as pipes depending on the size of the machine [30]. For larger parts, mandrels may be collapsible (inflatable or segmented) for easy extraction from the cured part. For small part volumes, soluble plasters, eutectic salts, and low melting alloys can be used to create the mandrel. Current research is looking into the ability of using FW to join parts together, as well as the ability to miniaturize the technology to create bench top sized FW machines [10, 33]. The use of programmable 
robots shows promise as a way to make filament winding obtainable to startup companies $[10,31]$. Companies currently using FW include Airborne Composites BV (Netherlands) [10], MF Tech (France), Spectrum Aeronautical LLC (USA), and Rocky Mountain Composites (USA), with the machines produced in the USA, France, Germany, the United Kingdom and Macedonia [8, 10].

For a quality composite part, the rovings must be in constant tension during application to provide good fiber collimation and reduce sagging. Voids are a common defect in FW parts; Rousseau et al. attributed the voids to the undulations that occur when a tow goes over and then under previously laid tows [34]. Micro-cracks can also form because of the resin rich nature of the undulating areas [34]. Voids can also come from bubbles in the resin bath when there is improper wetting of the fibers, and there is failure to uniformly wipe away excess resin $[35,36]$. Delaminations and fiber wrinkles are also found in FW parts. The bonding of dry layers to previously wound layers can lead to improper adhesion where delamination can occur [37]. Wrinkling of the fibers due to poor winding tension and misalignment within the rovings can cause defects in the final part [38].

\subsubsection{Automated tape layup (ATL)}

ATL was developed over 25 years ago. ATL machines lay a prepreg tape or continuous fabric strips with widths ranging from $75-300 \mathrm{~mm}$ onto a flat surface in various orientations $[7,27,39]$. Both thermoset and thermoplastic materials may be used in ATL. Creels of prepreg tape are stored near or on the head of the layup machine for use during production. The head of the ATL machine usually consists of spools of tape, a winder, winder guides, a compaction shoe or roller, tape cutter, and a position sensor as shown in Figure 3 [7, 40]. 


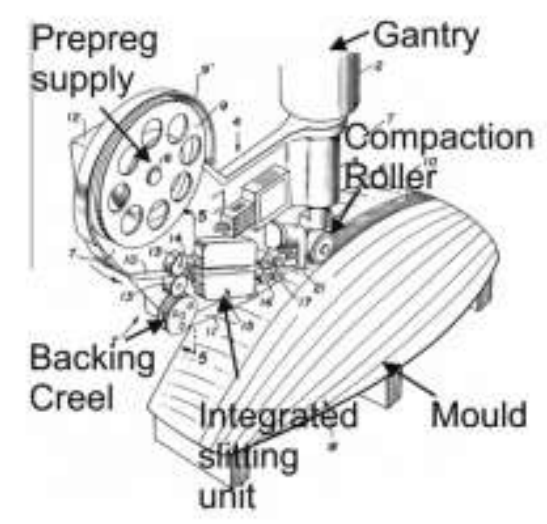

Figure 3: ATL head diagram showing tape laying over a curved mold [40]

A multi-axis articulating robot can be used to hold the ATL head, or it can be suspended above the tool on a gantry. When used with a gantry, the ATL head is able to have up to 10 degrees of freedom, with 5 axes on the head and 5 on the gantry [9]. The first step to composite production is depositing a starting amount of prepreg tape onto the mold using a soft silicone roller. After this is done, the machine deposits the tape according to CNC paths defining the part geometry. At the end of layup, the tape is cut automatically by rotating or pinching blades. The speed at which the machine does this is variable depending on the complexity of the part being created. This is a similar process to traditional AM technologies, where material is deposited in accordance with a defined CNC path.

For large noncomplex (flat or single curvature) parts, ATL is an efficient way to produce composite structures [39]. To create non-flat structures, a second forming step is used to shape the ATL laminate sheet [27]. The biggest problem with this is that the laminate has a tendency to warp and buckle during the forming process if the curvature is too large $[19,39,41]$. Analysis has shown that the two major components that influence buckling are the tackiness of the prepreg and the tow width [39]. The way to combat buckling is to enforce a minimum turning radius of the machine depending on the material 
and tow width being used [42]. As shown in Figure 4, MTorres has been developing smaller ATL machines that are able to lay down 3 inch tapes, as well as a flat laminate machine based off of small robots [43]. This shows the progress towards smaller scale ATL projects, making it more accessible to smaller companies [44].
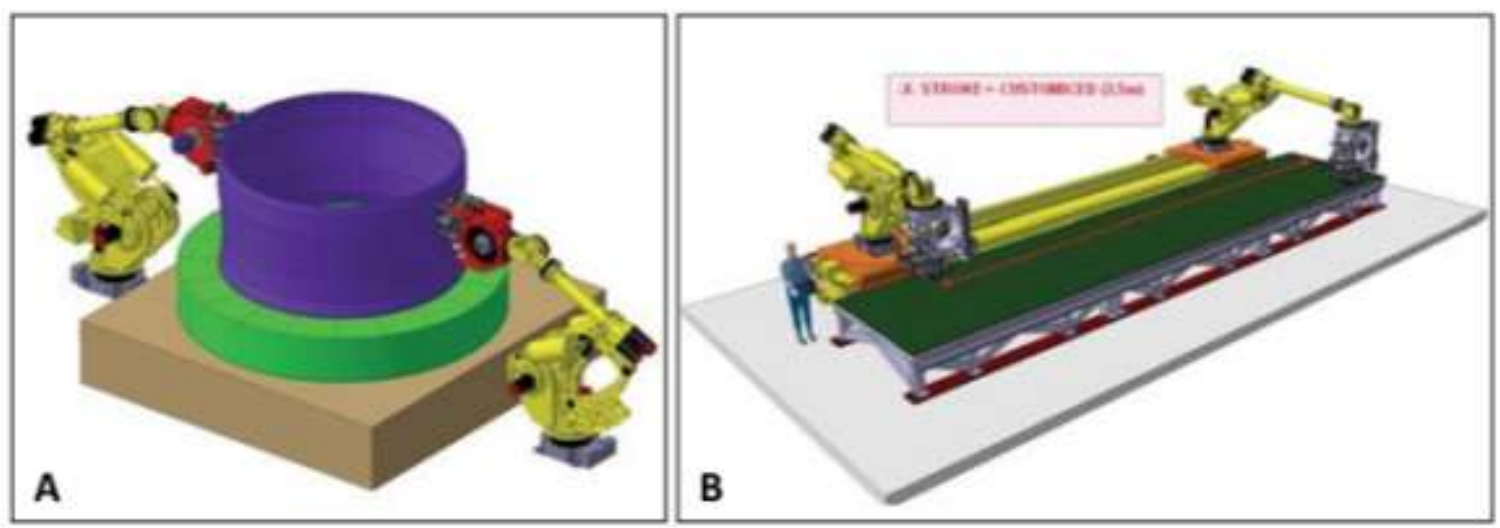

Figure 4: a) MTorres robotic arm ATL machines b) Small gantry style ATL machine (MTorres) [43]

\subsubsection{Automated Fiber Placement (AFP)}

AFP places 2-32 individual tows or ribbons of slit tape using low tension and compaction pressure [45]. This method can be used with both gantry style and robotic setups that hold the AFP head which are shown in Figures 5 and 6 [45]. The material is typically 0.125 in wide, and can be made from both thermoset and thermoplastic material. To deposit the thermoset-based prepreg tows, the AFP machine must be equipped with a cooled storage and rollers that are coated with a release agent [45]. Thermoplastic tows do not require the cooled storage, but the cutting and placement tools must be hardened to withstand the processing the harder type of plastic [45]. 


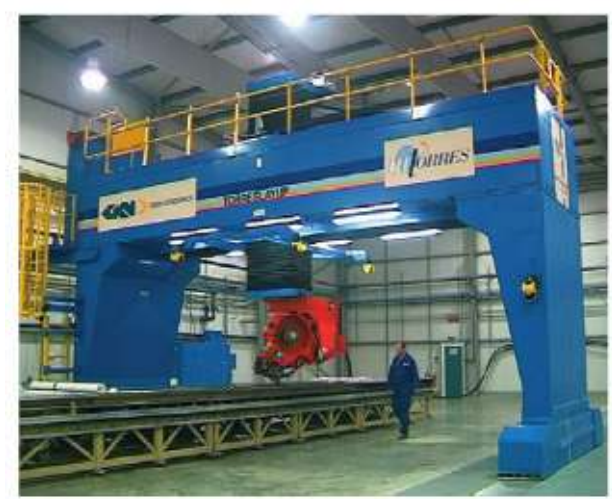

Figure 5: Gantry style AFP [45]

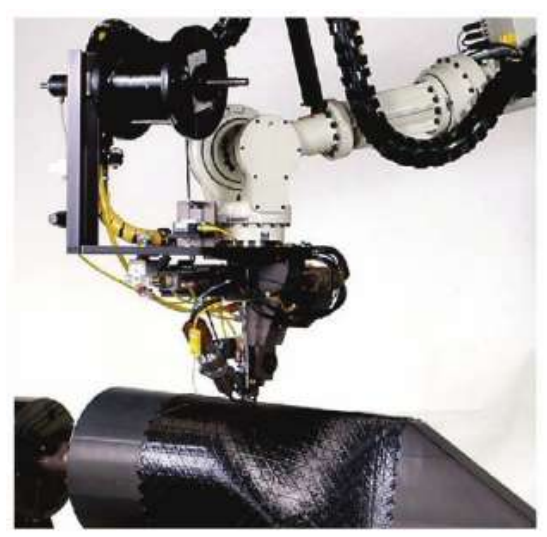

Figure 6: Robotic style AFP [45]

The AFP process makes use of individual tow control, or the ability to stop, cut and restart each tow during placement [28]. Individual tow control means each tow can be laid at its own speed, allowing for material to be deposited along a radius. By stopping individual tows, the width of the tape can also be changed, which allows variable width parts to be created.

The major limitation of possible AFP ply shape is the shortest tow length the machine can lay down, called minimum cut length [7]. A major issue of these using the AFP processes is the cost involved in acquiring the equipment necessary. Several manufacturers are moving towards using robotic arm style AFP machines to reduce the cost of these systems, like the machines by Coriolis Composites, Accudyne Systems, Electroimpact, and Automated Dynamics, which also boasts a small scale lab set up for research purposes, which is about the size of a CNC mill [46-49].

\subsection{Lab-Scale automation}

\subsubsection{Robotic pick and place techniques}

Angerer et al. proposed a robotic pick and place technique which uses a robotic arm, fitted with different end effectors, to cut and place prepreg or dry fabric to create composite 
laminates $[6,20]$. Robotic pick and place techniques are believed to be able to replace the previously mentioned AFL and AFP systems [6]. This method is less mature than AFL and AFP, and no full scale production method has been used [6]. The current issue with this method is the time it takes to perform the task, where the most time intensive process is the removal of the paper backing from the prepreg [6]. To combat this problem, different end effectors must be developed that can efficiently cut and remove prepreg backing, and arrange the prepreg material within the desired mold. Assyst Bullmer in the UK is currently selling a composite manufacturing cell that consists of a computer-aided design program and their robotic arm fiber cutter machine [50].

\subsubsection{Continuous Tow Shearing (CTS)}

CTS modifies AFP technology to produce tighter curvature without gaps, cuts, and overlaps in the tow placement [41]. The main differences in CTS compared to AFP are the materials being used during layup and the path layout $[19,41]$. 


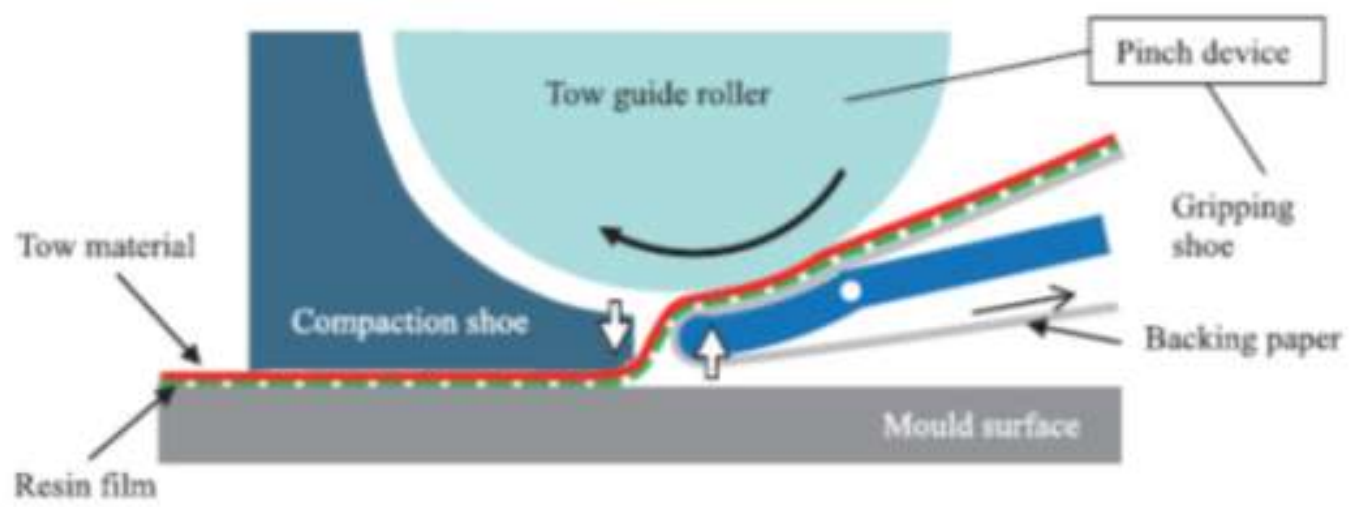

Figure 7: CTS machine set-up [19]

In CTS, a specially designed head takes dry carbon fiber tows and applies a layer of resin film to one side, as seen in Figure 7 [19]. This semi-impregnated tow is then applied to the mold via a modified CNC ply cutting machine. This results in a material comparable to commercially available prepreg materials, with a random void distribution [41]. The error found in the curvature of the part compared to the path was at maximum $5^{\circ}$ but was on average $2^{\circ}$ [41]. CTS is able to approach curvature values more than 10 times that of conventional AFP due to the ability to place dry tows [41]. However, inaccuracy in some of the paths and slight tow bending makes it still a design in progress.

\subsection{Conclusion}

Composite automation is used in various industries. The automation process necessitates simple part design but the ability to change the design quickly is not without major cost. Because of this design complexity, composite materials cannot be used to their full extent and benefit, which is true for any manual lay-up and assembly. As Timothy Gutowski said, "The challenge that faces industry now is to develop flexible methods of automation that can significantly expand the window of shape and microstructure available to the designer at reasonable cost" [51]. ATL and AFP are working towards this flexibility, 
and there are also ways of textile weaving that can allow for higher degrees of freedom during fabrication. The fiber layup mechanism and the fiber -to -wetting- to -solidification process are two issues that need to be resolved to create better automated processes for functional composites. [51]. To create a process that could fully encapsulate these two issues quickly would allow for better automated process for composites.

a Filament Winding $\quad$ AFP $\quad$ ATL Additive Manufacturing of Composites

10000

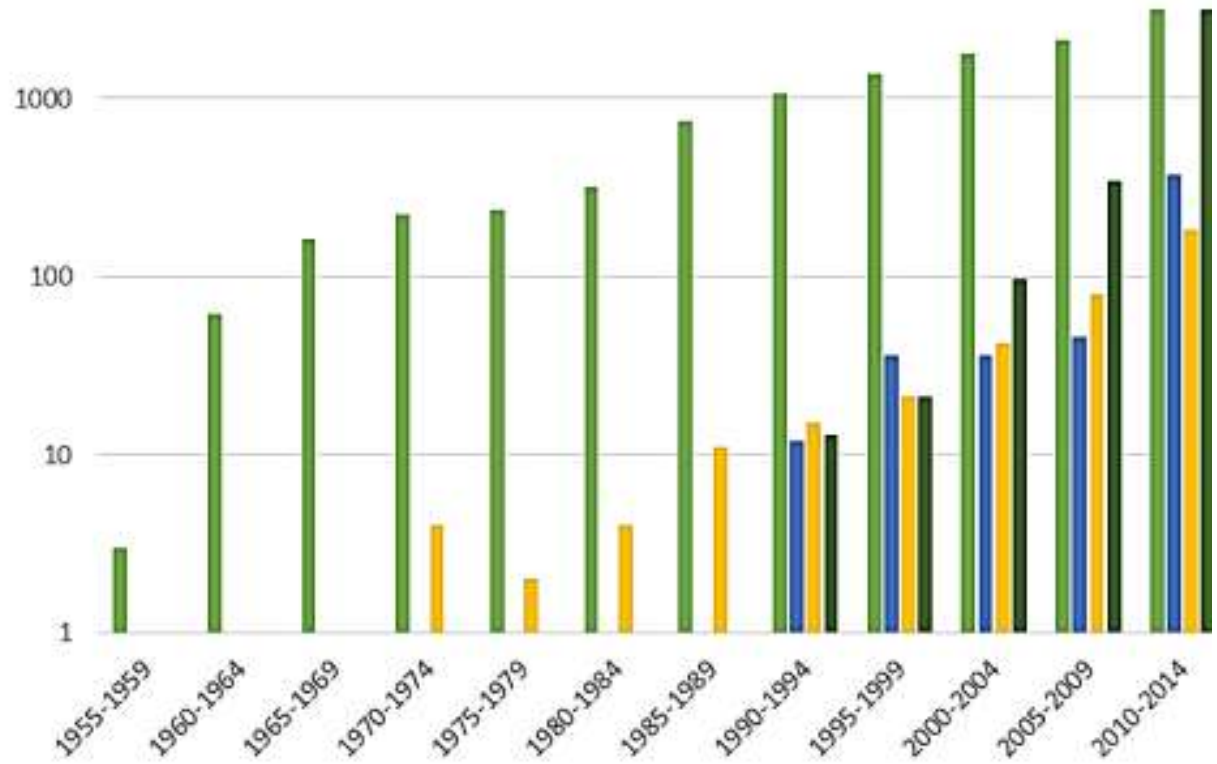

Figure 8: Number of papers considering FW, AFP, ATL, and Additive Manufacturing in 4 year intervals (data from Google Scholar)

AFP, ATL and FW are industrial benchmarks for automated methods to evaluate developing processes. Research on automated methods for creating thermoset composites has been over the span of the time line, as seen in Figure 8. The number of published papers on AFP and ATL has steadily risen over the past few years, while the number of papers on 
additive manufacturing of composites has recently reached the same level as filament winding.

\section{ADDITIVE MANUFACTURING: POLYMER COMPOSITES}

Many methods of additive manufacturing (AM) exist [52], each suited to different materials and different needs. Applications range from printing new organs [53] and cranioplasty [54], to creating lightweight parts [55], fuel cells [56] and even art [57]. Parts created from additive manufacturing can be complex and customized, without the need for expensive mold redesign as would be needed for injection molding. The main issue with additive manufacturing is the lack of materials with structural capabilities. Current materials typically are not robust enough to be used as an end-product or component [58]. Additionally, additive manufacturing has the constraint of working "in-the-box", and is constrained to the size of the print area [59]. The average size of a large industrial printer is around $1 \mathrm{~m}^{3}$, although recently a build area of $26 \mathrm{~m}^{3}$ has been implemented at Oak Ridge National Laboratory using their Big Area Additive Manufacturing machine [60].

Recently, attention has been focused on the ability of additive manufacturing to create structural parts for the use in building end-product components [61-63]. Composite material in particular suits this process, since most AM processes already use the matrix polymers (i.e. thermosets and thermoplastics) that are the key components of fiber reinforced composites [64]. From creating thermoplastic filament preloaded with fibers [24] to mixing fibers with powdered plastic base of some processes [22], research is heading towards quickly realizing a fully printable, functional composite part. The below sections (1) review 
the capabilities of various AM composite methods and (2) provide insight into the composite micro-structure of layered prints.

\subsection{Vat Photopolymerization}

Liquid-based additive manufacturing systems started with Chuck Hull in the mid 1980's, when he created a part using a laser and ultra violet light (UV)-curable materials.

The company 3D Systems used this knowledge to sell machines that could "rapidly prototype" parts [65]. This method is termed vat photopolymerization by ASTM F2792 standards, but may also be referred to as stereolithography (SLA). Many variations of this process are being used today in makers such as Polyjet, as well as several other industrial printing systems [66].

The basis of vat photopolymerization systems come from depositing photo-polymer by either wiping resin over the part [67], depositing resin via inkjet method [68], or incrementally submerging the part into a vat of photopolymer. This additional layer is cured using photo-polymerization into a solid polymer. SLA typically uses UV light for curing, but some systems are able to use visible light [12]. Projection stereolithography uses digital light processors and is able to create slices without scanning by using a mask [69]. This reduces the fabrication time greatly while still allowing high feature resolution [70]. 


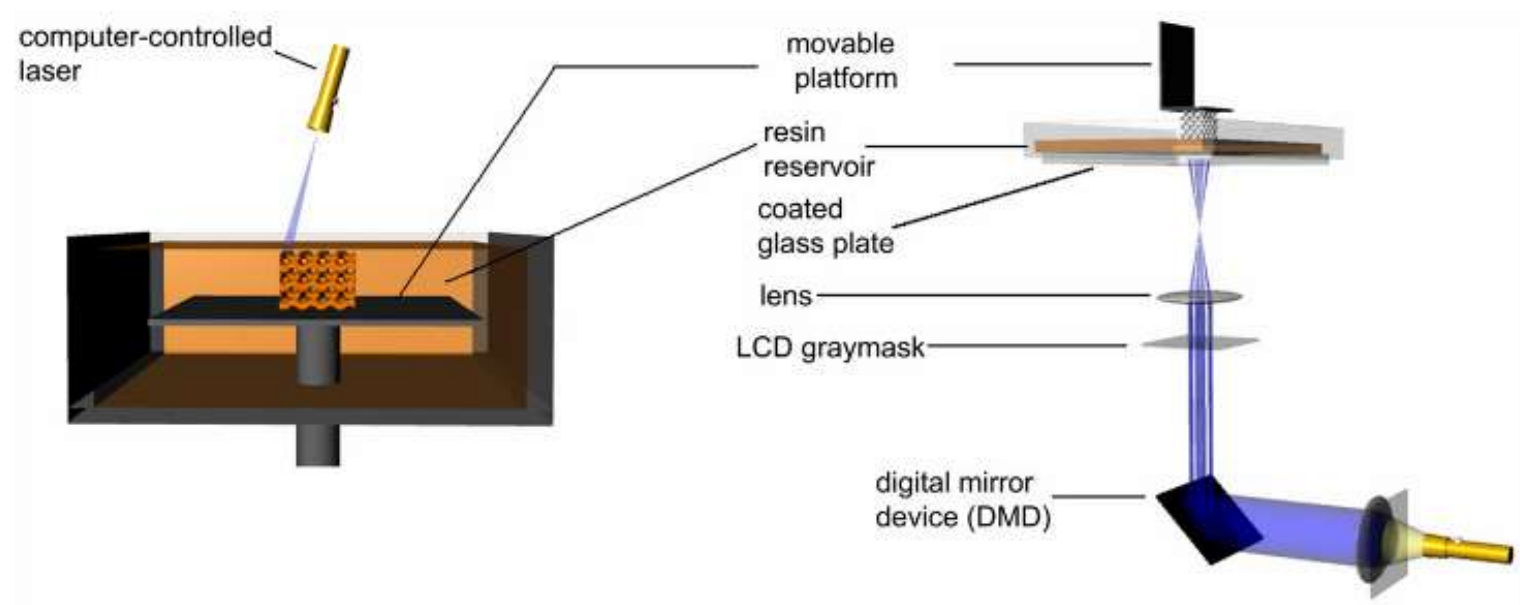

Figure 9: Parts created using the bottom up approach of stereolithography on the left, and the top-down approach shown right_[11]

Most of the existing SLA systems implement a bottom up approach, scanning each layer, then subsequently moving the base downwards and wiping an additional layer of polymer on top before again photo-polymerizing $[11,12,69,70]$. In addition, several top down approaches have also been created. Figure 9 depicts both approaches [11]. The main criticism of top down approaches is that each time a layer is polymerized, extra stress is exerted on the part in order to detach it from the bottom of the dish. However, this stress has said to have a negligible effect on the part, and the products made in this manner have smoother surfaces, use less material and are not as oxygenated as their "bottom up" counterparts [11].

A new method called Continuous Layer Interface Production (CLIP) was created to alleviate the problem of detaching from the vat surface due to a highly oxygenated layer that inhibits resin curing [71]. Designed as a layer scanning method, resin is replenished as the cured layers are pulled up out of the vat, due to the suction created by the part moving upwards. The dead zone (highly oxygenated zone where resin cannot cure) thickness is 
controlled by the product of the photo initiator concentration $\left(D_{c 0}\right)$, the wavelength dependent absorptivity $\left(\alpha_{P I}\right)$, the number of incident photons at the imaging plane per area time $\left(\Phi_{0}\right)$, and a proportionality constant $(\mathrm{C})$ following the function given in Equation (1).

$$
\text { Dead Zone Thickness }=C\left(\frac{\Phi_{0} \alpha_{P I}}{D_{C 0}}\right)^{-0.5}
$$

The creation of the dead zone allows for the ability to use a bottom up approach to SLA where the resin replenishes the print zone automatically due to the infill of resin as the solidified layer moves upwards. The inventors claim this process is up to a hundred times faster than what is currently commercially available. The process is faster because the resin replenishing and UV exposure are continuous rather than a series of discrete steps, making the resin cure rate and viscosity limiting factors. The continuous layer creation process yields parts with high resolution.

Vat photopolymerization can create composite parts from chopped, woven, or continuous fibers. The creation of composite parts consists of submerging the reinforcing fibers in the UV-curable resin, then curing the resin [72]. This method to make composites with discontinuous fibers is only slightly modified from the original wiper method: a mixer is added to keep the fibers from settling during the cure process [73]. It has been reported that a fiber volume fraction of $20 \%$ is the upper limit for this method, due to increased viscosity with increasing fiber content causing issues with the application of thin layers [73]. One way to overcome the high viscosity is to deposit the resin fiber mixture with a nozzle, before going over the deposited layer with a wiping device that smooths the surface $[67,74,75]$. Figure 10 is an example of the method that has been used with discontinuous fibers, allowing easy deposition of the fiber-doped resin [67]. Figure 10(a) shows the 
bottom platform of the vat moving down an incremental amount. Figure 10(b) shows a nozzle depositing the fiber-doped resin on top of completed layers. A wiper then smooths the top of the deposited resin in Figure 10(c), before a laser cures the corresponding layer pattern in Figure 10(d). To incorporate a woven mat of fibers, the woven fiber mat is placed on a bottom layer of solid resin, then coated with resin as in other SLA methods. A problem with this procedure is that the wiper could shift the fiber mat during printing [72].

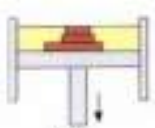

(a)

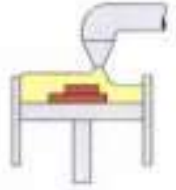

(b)

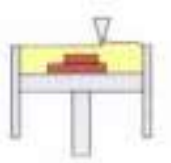

(c)

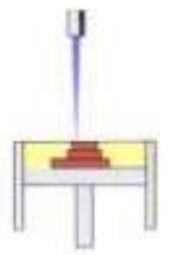

(d)

Figure 10: Rapid layer composite manufacturing system [67]

Fiber-reinforced micro-parts with aligned ferromagnetic fibers can be created using a similar method, then magnetically aligning the fibers [76]. Using this method, fiber orientation can be changed within different layers of the part, depending on the magnetic field, which leads to highly customizable parts in terms of direction of anisotropic properties like strength. However, the mechanical properties and interfacial strength of the method have yet to be tested [76].

Figure 11 shows the vat photopolymerization composite with the highest strength (72 MPa), formed with special addition of interlayer bonding sites [74]. The idea behind interlayer bonding is that small sections of composite are left uncured, such that when the next layer is deposited, some of the fibers are able to transcend the layer boundary, thus causing better bonding between the layers [74]. It has been theorized that the ultimate strength of the composite is less affected by the addition of fibers than the modulus, 
because the weakest point in a printed composite is the interlayer bonding [75]. Since fibers do not typically transcend layers, the strength between layers is purely due to the matrix interface.

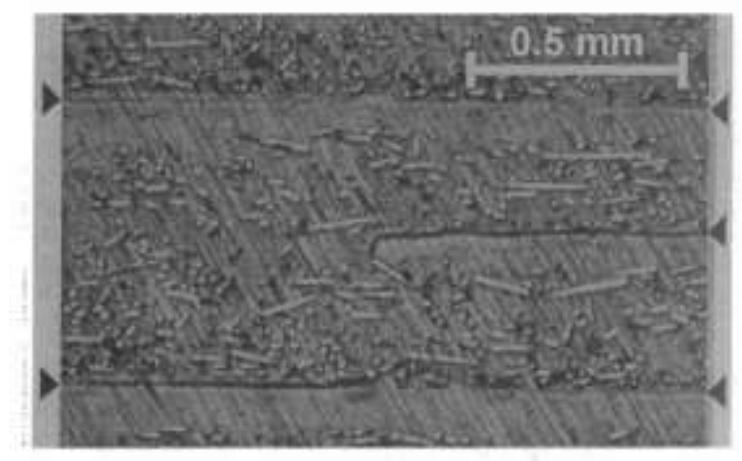

Figure 11: Cross section of SLA composite created with rivets [75]

Work has been done by Zak et al. to model the modulus and strength of the composite using the distribution of the orientation of the fibers, leading to a modified rule of mixtures (ROM) for printed composites [74]. The modified ROM takes into account non-alignment of fibers during printing. The modulus can thus be found via equation (2),

$$
E_{c}=\chi_{1} \chi_{2} v_{f} E_{f}+v_{m} E_{m}, 0<\chi_{1}<1
$$

where $\chi_{1}$ is orientation efficiency factor and is estimated by equation (3), $\chi_{2}$ (equation (4)) and $\chi_{4}$ (equation (6)) are fiber length distribution correctors, and $\chi_{3}$ (equation (5)) is the orientation efficiency factor [74]

$$
\begin{gathered}
\chi_{1}=\frac{\sum_{k=1}^{n} E_{\phi k} t_{k}}{E_{1} \sum_{k=1}^{n} t_{k}} \\
\chi_{2}=\sum_{k=1}^{m} P_{s k}\left(1-\tanh \left(n s_{k}\right) / n s_{k}\right) \\
\chi_{3}=\frac{\sum_{k=1}^{n} \sigma_{u \phi_{k}} t_{k}}{\sigma_{u 1} \sum_{k=1}^{n} t_{k}}
\end{gathered}
$$




$$
\chi_{4}=\sum_{k=1}^{m} P_{s l k}\left\{1-\frac{s_{c}}{2 s_{k}}\right\}+\sum_{k=1}^{m} P_{s s k} s_{c} / 2 s_{k}
$$

In these equations, $t_{k}$ is thickness of the $k^{\text {th }}$ lamina panel, $\phi$ is the angle at which the fibers are aligned in respect to the $\mathrm{z}$ direction, $s$ is the aspect ratio of the fibers of length $l, s_{c}$ is the critical aspect ratio for the composite, $E_{l}$ is modulus for perfectly aligned fibers, $E_{\phi}$ is modulus along the $z$ direction for fibers aligned at angle $\phi$, and $P_{s}$ is a weighting factor proportional to the total volume of all fibers of length $l$.

The stress of the composite is also determined using the parameters $\chi_{3}$ and $\chi_{4}$ as well as the fiber volume fraction $v_{f}$, fiber ultimate strength $\sigma_{f u}$, the matrix volume fraction $v_{m}$, and matrix ultimate strength $\sigma_{m}^{*}$, as shown in equation (7).

$$
\sigma_{c}=\chi_{3} \chi_{4} v_{f} \sigma_{f u}+v_{m} \sigma_{m}^{*}
$$

Cheah et al. [73] reported good correlation between the above equations and their results, but Shofner et al. [23] reported that using rule of mixtures was orders of magnitude higher than what was found experimentally. Cheah et al. utilized cross sectional images of SLA composites, as shown in Figure 12, to determine the distribution of fibers in the composite. From the images it was determined that the fibers are distributed within the composites at various degrees near parallel to the direction of the resin wiping during the layer deposition. Figure 13 shows the fiber orientation distribution [73]. This kind of distribution creates an anisotropic composite with stronger properties along the wipe direction, in this case from 0 to 10 degrees. 


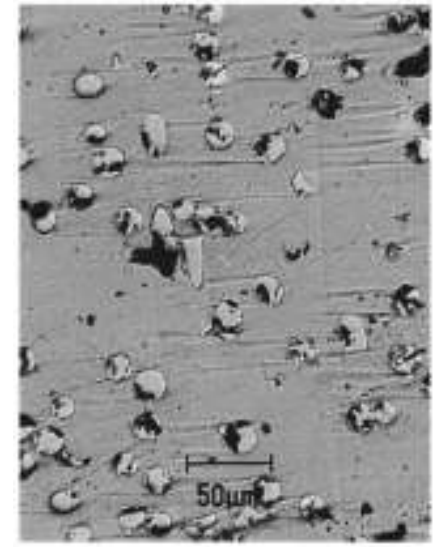

Figure 12: Cross section of $20 \%$

GFRP fabricated via SLA [73]

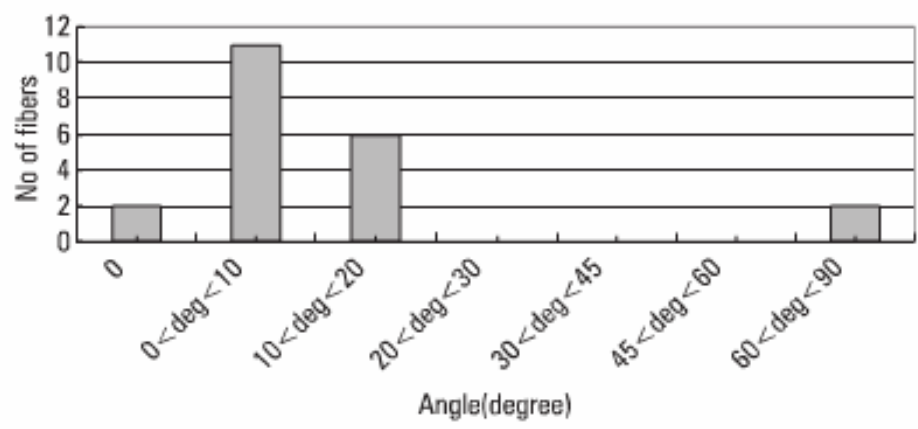

Figure 13: Distribution of fiber orientation in composite with respect to wipe direction [73]

Overall, the vat polymerization method, though functional with non-reinforced polymers, has issues when fibers were added due to the increase in viscosity of the resin [75]. Combating this issue led to the creation of the deposit method, where the resin fiber mixture was extruded by nozzle in a more precise manner, and then leveled off using a wiper $[67,74,75]$. Finally, in order to create stronger composites, more thought must go into ways to create interlayer bonding such that stress concentrations will not build up at the layer boundaries. The majority of the methods to print composites using SLA yields composites that have $1-5 \%$ the strength and modulus of a typical continuous composite material made with standard methods, and about half the strength of chopped fiber composites. The strongest printed composites are those that have strong interfacial bonding between layers, use mats of woven material, and use a higher laser power during fabrication.

The vat photopolymerization process has several problems that occur due to 1) the mechanics of fiber addition, 2) fiber settling, 3) formation of bubbles (voids), 4) increase in resin viscosity (causes poor mixing, leading to poor interfacial properties [77]), and 5) laser 
diffraction (long cure time) caused by diffraction of laser energy by the liquid and particulates[72, 73]. However, vat photopolymerization can be used to created glass fiber reinforced samples with increased modulus and strength, as compared to neat resin $[72,73]$. For example, Karalekas et al. found that the addition of woven glass fiber mats increased the resin modulus from $1.90 \mathrm{GPa}$ for acrylic-based resin to $2.85 \mathrm{GPa}$, and the strength increased from 37.1 MPa to 55.2 MPa. Additional results from this and other papers are summarized in Table 1. The highest moduli in Table 1 are from Karalekas et al., who made use of non-woven mats in their composites, and Cheah et al., who found that higher laser power and lower laser pitch can increase final composite strength $[73,78]$. However, vat photopolymerization composites still do not reach standard strength (100-300 MPa) and stiffness (3-20 GPa) of chopped fiber composites manufactured using means such as vacuum bagging or autoclave processing $[32,79]$. Even with the use of fiber mats, composites created by vat photopolymerization have only a fraction of the modulus and strength of typical composites. 
Table 1 Strength and modulus of composites created from vat photopolymerization

\begin{tabular}{|c|c|c|c|c|c|c|}
\hline Material & $\begin{array}{l}\text { Test } \\
\text { (Standards }\end{array}$ & $\begin{array}{l}\text { Fiber } \\
\text { Content }\end{array}$ & Print method & $\begin{array}{l}\text { Modulus } \\
\text { (GPa) }\end{array}$ & $\begin{array}{l}\text { Strength } \\
\text { (MPa) }\end{array}$ & REF \\
\hline \multirow{5}{*}{$\begin{array}{l}\text { Glass Fiber- } \\
\text { SL5170 resin }\end{array}$} & \multirow{5}{*}{$\begin{array}{l}\text { Tensile (ASTM } \\
\text { Standard } \\
\text { Method D638- } \\
\text { 91a, Type M- } \\
\text { III) }\end{array}$} & $\sim 13$ & NA & $\sim 1.75$ & $\sim 59$ & \multirow[t]{5}{*}[75]{} \\
\hline & & $\sim 16$ & NA & $\sim 2.5$ & $\sim 65$ & \\
\hline & & $\sim 22.5$ & NA & $\sim 2.6$ & $\sim 66$ & \\
\hline & & 20 & Uncured rivets & 1.96 & 44 & \\
\hline & & 20 & No rivets & 1.57 & 44 & \\
\hline \multirow{4}{*}{$\begin{array}{l}\text { Glass Fiber- } \\
\text { urethane } \\
\text { acrylic photo } \\
\text { polymer }\end{array}$} & \multirow{4}{*}{$\begin{array}{l}\text { Tensile (ASTM } \\
\text { Standard Test } \\
\text { Method D638) }\end{array}$} & \multirow[t]{4}{*}{20} & $\begin{array}{l}\text { Laser Power } \\
70 \mathrm{~mW}\end{array}$ & $\sim 2.6$ & $\sim 27.5$ & \multirow[t]{4}{*}[73]{} \\
\hline & & & $100 \mathrm{~mW}$ & $\sim 2.8$ & $\sim 27.5$ & \\
\hline & & & $130 \mathrm{~mW}$ & $\sim 3$ & $\sim 28$ & \\
\hline & & & $160 \mathrm{~mW}$ & $\sim 3.2$ & $\sim 29$ & \\
\hline \multirow[t]{2}{*}{$\begin{array}{l}\text { Glass Fiber- } \\
\text { SL5170 resin }\end{array}$} & \multirow[t]{2}{*}{$\begin{array}{l}\text { Tensile } \\
\text { (dogbone) }\end{array}$} & 16 & $\begin{array}{l}\text { Large interlayer } \\
\text { bonding sites }\end{array}$ & 2.48 & 71.8 & \multirow[t]{2}{*}{ [74] } \\
\hline & & 17 & $\begin{array}{l}\text { Small interlayer } \\
\text { bonding sites }\end{array}$ & 2.49 & 72.0 & \\
\hline \multirow[t]{2}{*}{$\begin{array}{l}\text { E-glass Fiber- } \\
\text { Acrylic resin }\end{array}$} & \multirow[t]{2}{*}{$\begin{array}{l}\text { Tensile } \\
\text { (dogbone) }\end{array}$} & $\begin{array}{l}\text { Non-woven } \\
\text { mat }\left(7 \mathrm{~g} / \mathrm{m}^{2}\right)\end{array}$ & NA & 2.23 & 43.6 & \multirow[t]{7}{*}[72]{} \\
\hline & & $\begin{array}{l}\text { Non-woven } \\
\text { mat }\left(17 \mathrm{~g} / \mathrm{m}^{2}\right)\end{array}$ & NA & 2.85 & 55.2 & \\
\hline \multirow{2}{*}{$\begin{array}{l}\text { Carbon } \\
\text { Fiber-Acrylic } \\
\text { resin }\end{array}$} & \multirow[t]{2}{*}{$\begin{array}{l}\text { Tensile } \\
\text { (dogbone) }\end{array}$} & $\begin{array}{l}\text { Non-woven } \\
\text { mat }\left(7 \mathrm{~g} / \mathrm{m}^{2}\right)\end{array}$ & NA & 1.81 & 43.6 & \\
\hline & & $\begin{array}{l}\text { Non-woven } \\
\text { mat }\left(17 \mathrm{~g} / \mathrm{m}^{2}\right)\end{array}$ & NA & 2.51 & 42.2 & \\
\hline $\begin{array}{l}\text { Aramid fiber- } \\
\text { acrylic resin }\end{array}$ & $\begin{array}{l}\text { Tensile } \\
\text { (dogbone) }\end{array}$ & $\begin{array}{l}\text { Non-woven } \\
\text { mat }\left(17 \mathrm{~g} / \mathrm{m}^{2}\right)\end{array}$ & NA & 2.07 & 29.9 & \\
\hline \multirow[t]{2}{*}{$\begin{array}{l}\text { E-glass - } \\
\text { epoxy resin }\end{array}$} & \multirow[t]{2}{*}{$\begin{array}{l}\text { Tensile } \\
\text { (dogbone) }\end{array}$} & $\begin{array}{l}\text { Non-woven } \\
\text { mat }\left(34 \mathrm{~g} / \mathrm{m}^{2}\right)\end{array}$ & NA & 2.76 & 42.2 & \\
\hline & & $\begin{array}{l}\text { Non-woven } \\
\text { mat }\left(50 \mathrm{~g} / \mathrm{m}^{2}\right)\end{array}$ & NA & 2.35 & 39.1 & \\
\hline \multirow[t]{4}{*}{$\begin{array}{l}\text { E-glass- } \\
\text { Epoxy }\end{array}$} & \multirow[t]{4}{*}{$\begin{array}{l}\text { Tensile } \\
\text { (dogbone) }\end{array}$} & $\begin{array}{l}\text { Non-woven } \\
\text { mat }\left(7 \mathrm{~g} / \mathrm{m}^{2}\right)\end{array}$ & NA & 2.55 & 50.2 & \multirow[t]{6}{*}[78]{} \\
\hline & & $\begin{array}{l}\text { Non-woven } \\
\text { mat }\left(17 \mathrm{~g} / \mathrm{m}^{2}\right)\end{array}$ & NA & 2.72 & 41.7 & \\
\hline & & $\begin{array}{l}\text { Non-woven } \\
\text { mat }\left(34 \mathrm{~g} / \mathrm{m}^{2}\right)\end{array}$ & NA & 2.76 & 42.2 & \\
\hline & & $\begin{array}{l}\text { Non-woven } \\
\text { mat }\left(59 \mathrm{~g} / \mathrm{m}^{2}\right)\end{array}$ & NA & 2.35 & 39.1 & \\
\hline \multirow[t]{2}{*}{$\begin{array}{l}\text { E-glass - } \\
\text { polyurethane }\end{array}$} & \multirow[t]{2}{*}{$\begin{array}{l}\text { Tensile } \\
\text { (dogbone) }\end{array}$} & $\begin{array}{l}\text { Non-woven } \\
\text { mat }\left(30 \mathrm{~g} / \mathrm{m}^{2}\right)\end{array}$ & NA & 2.96 & 48.7 & \\
\hline & & $\begin{array}{l}\text { Non-woven } \\
\text { mat }\left(59 \mathrm{~g} / \mathrm{m}^{2}\right)\end{array}$ & NA & 3.12 & 49.1 & \\
\hline
\end{tabular}




\subsection{Binder Jetting}

Powder-based printing that uses binder jetting fuses a powder together by a sprayed on binder material or glue. This method was initially termed 3D printing, but has changed to binder jetting with the adoption of ASTM standard F2792. The steps involved can be seen in Figure 14 [80]. First, a layer of powdered material is spread by a roller into a thin layer on a moveable platform. A solvent, or binder liquid is then jetted onto the powder layer, bonding together the particles that make up the powder bed. The platform then moves down a specified amount and an additional layer of powder is deposited. This process repeats until the part is finished. The binder material can either be a liquid that reacts with the powder to solidify the part, or a liquid binder that adheres the powder to itself.

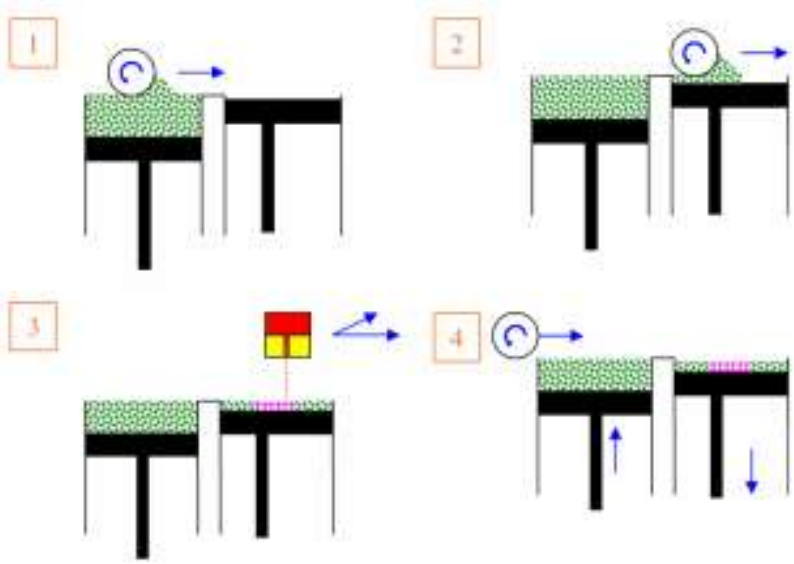

Figure 14: The steps of 3D printing 1) powder is rolled onto the build area 2) the powder is smoothed and slightly compressed 3) a nozzle deposits the binder fluid onto the bed of powder 4) the build station moves down while the powder bed piston moves up allowing the process to begin again [80]

Like powder bed fusion, binder jetting is able to make use of a wide range of powdered materials such as plastics, metals and ceramics. The ability to print with powder means that the support of the structure is built in to the fabrication, so printing overhangs on parts take less time than while using a liquid-based manufacturing system [80]. This process also 
takes place at room temperature, reducing complexity of needed equipment. The problem encountered using binder jetting to create composites is the low strength of the green part before the final processing occurs. The strength of the green part solely depends on the binder adsorption and mechanical interlocking of the powder [81]. Powder can also become trapped inside the body of the part. The liquid chosen as the ink of the process needs to be able to have the material properties necessary for fusion; not many materials can be used in this process.

Little has been done in terms of fabricating composites using binder jetting techniques because of the difficulty of jetting fiber or wetting of a fiber-polymer blend. Polymer fibers and glass fibers, to improve the green strength of the parts, were successfully introduced into a ceramic composite using binder jetting [15]. The fibers were sieved, then mixed in with the powder bed, and a binder was jetted on to make the parts. Unfortunately, most of the parts were too weak to be removed from the build chamber without an infiltration of polymer. In another experiment, carbon nanofibers were dispersed in epoxy to increase conductivity [82]. The nanofibers were small enough (i.e. $100 \mathrm{~nm}$ diameter and 50-200 $\mu \mathrm{m}$ long) that the fibers were mixed in the resin and infilled after the binder jetting process [82]. Both papers showed that the created composite was too weak without adding an additional binding step. To date, no mechanical testing of reinforced polymer composites created by powder bed processing with liquid binder has been attempted.

\subsection{Material Extrusion}

Material extrusion composite additive manufacturing can be divided into two major subsections, depending on the feed material used: (1) thermoplastic material and (2) thermosetting resin. For thermoplastic materials, a heated nozzle melts the polymer-fiber 
blend and deposits it onto a surface. Thermosetting resin is less commonly used as an additive manufacturing material, but is rapidly gaining favor in additive manufacturing because of the resins' strength and toughness [16].

\subsubsection{Thermoplastic Material Extrusion}

There are several different ways that solid materials are used as printing materials in additive manufacturing. The most well-known is material extrusion, which is also termed fused deposition modeling (FDM) when used with thermoplastic polymers. In this process raw polymer filament is fed through a heated nozzle until it is liquefied, and then layered on a heated platform. This system typically uses a thermoplastic material as the structural material along with a support material that is used to support pieces that may overhang the previous layers. The support material is removed during post processing. Thermoplastic material extrusion is able to achieve high resolution printing $(0.0254 \mathrm{~mm})$ in the $\mathrm{x}, \mathrm{y}$ and $\mathrm{z}$ directions. The ease of use and the low toxicity of the printed material gives this method the ability to be used in office settings. However, because of the way the material is extruded, the printed material is confined to those materials which can be melted by the nozzle and then cooled and solidified on the print surface. The round nozzle shape used in most material extrusion printers makes it difficult to achieve sharp external corners in parts [65].

The material feed rate sets the speed of the part production: if a process is able to increase the melting and depositing of the material, the scan rate can be increased. Another way that systems improve the speed of creation is by using an infill pattern, such as honeycomb. This infill pattern means the part is mostly hollow and helps by saving material and time while printing. In order to achieve high strength of the parts, the path of 
printing has to be changed during layers, since strength between deposited layers is weaker than that along the print direction.

Thermoplastics used in printing fiber reinforced composites using material extrusion include, polyetheretherketon (PEEK), polycarbonate, Poly(methyl methacrylate) (PMMA), polylactic acid (PLA) and ABS [23, 83, 84]. Chopped fiber is most often used in material extrusion, where the fibers are mixed in with a thermoplastic, then extruded, creating coils of a fiber reinforced plastic. This reinforced plastic feedstock is then used within the rapid prototyping machine by feeding through a heated nozzle $\left(205^{\circ} \mathrm{C}\right.$ for $\mathrm{ABS}$ doped with carbon fiber) to soften and depositing on a platform (heated to $85^{\circ} \mathrm{C}$ for $\mathrm{ABS}$ doped with carbon fiber) where the material cools and solidifies. Chopped fibers are typically the reinforcement of choice, be it glass or carbon fiber. It has been noticed in several cases that breaking of the fibers occurs during processing and mixing, and thus the fibers have a lower average length than the original fiber composition $[24,85]$.

Recently, several projects in industry and academia have demonstrated reinforced thermoplastic material extrusion using continuous carbon fiber filaments $[86,87]$. Two commercial printers from MarkForged, have demonstrated the printing of nylon reinforced with glass, carbon, and Kevlar fiber (i.e. MarkOne and MarkTwo) [86]. A study conducted by F. vand der Klift et al. [88], showed that although the printer does print continuous fibers, the path planning and slicing algorithm on the MarkOne allows for cuts within the part in order to not become "stuck", by running into the previous deposited layer, while printing. For instance, to create a square piece, the printer must move inward once while completing the first pass around the perimeter of the part. This allows for a discontinuity in the part at the area where the print head moved inside this perimeter, as shown in Figure 15. 
Another disadvantage found with printing continuous fibers stems from the need to include a layer of pure thermoplastic on the bottom and top layers. These non-reinforced layers serve to help the fiber reinforcement stick to the platform as well as keep the fibers from disintegrating when the part is removed. The fiber volume fraction was found to be around $34.5 \%$ in the samples printed from the MarkOne [88].

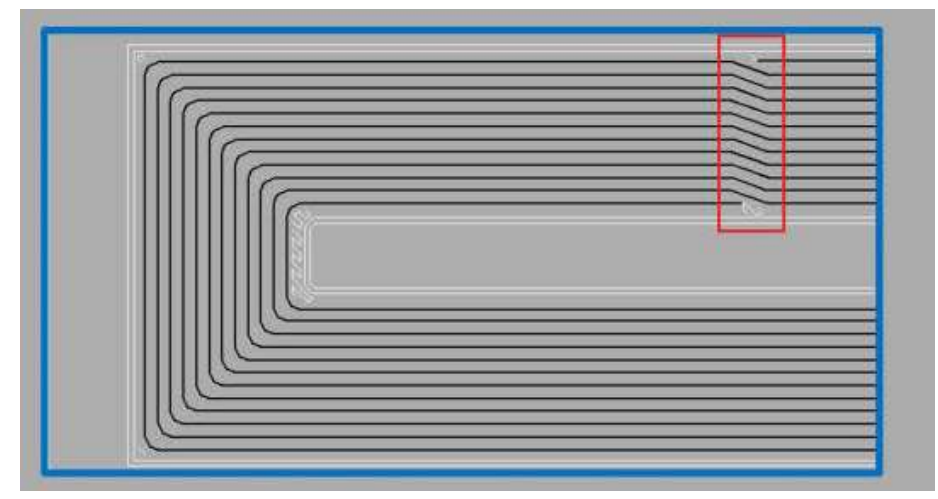

Figure 15: MarkOne print path discontinuities [88]

One way to print a continuous fiber composite is by using a continuous fiber coated in thermoplastic as filament; another is to merge a tow of fiber with a neat polymer filament during the extrusion process [86, 87]. Work by Matsuzaki et al. [89], has recently created a continuous fiber printing system where carbon and jute continuous fibers are mixed with polylactic acid within the nozzle before being printed. When printing with carbon fiber, a preheating element was used to heat the fibers before the consolidation within the nozzle, whereas the jute fibers were unheated in order to not damage the fibers, as high temperatures during extrusion has shown to cause decomposition of the jute resulting in voids[90]. Additionally, there is currently a 3D printer in development that prints continuous carbon fiber filaments with epoxy resin, by wetting the fiber before extrusion and using a UV laser to solidify the resin during printing [91]. Additionally, Gardner et al. [92] have recently printed composites using Ultem 1010 and carbon nanotube (CNT) yarn. 
One of the issues with printing continuous fibers is the adhesion of the fiber to the print bed to begin the deposition process. To achieve this, the nozzle was advanced along the printing surface until adhesion occurred, and printing commenced. Parts made from CNT yarn are conductive as well as structural, creating multifunctional parts. The structural testing showed the CNT composites have a strength around $125 \mathrm{MPa}$ and a Young's modulus of 3 GPa, within the expected range given by The Rule of Mixtures. By using CNT yarn, $180^{\circ}$ turns were achievable during printing without gaps in the composite. Even greater mechanical results could be achieved with better fiber wetting [92].

A problem that plagues thermoplastic material extrusion composite printing is the voids created in the composite when printing $[23,24]$. Though the inclusion of fibers within the filament improves the strength of the printing filament (from $24.5 \mathrm{MPa}$ up to 58.60 MPa $[93,94])$, Tekinalp et al. showed that the inclusion of fibers initially decreases the interlayer bonding by increasing the amount of voids, compared to that of a compression molded sample [24]. Figure 16shows the comparison between the samples [24]. However, as the volume fraction of fibers increase, these voids begin to decrease in size, increasing the interlayer bonding. It is suspect the increased bonding is due to fibers transcending the layers, in agreement with Zhong et al.'s work [24, 93]. The coefficient of thermal expansion of the carbon fiber helps in this situation, reducing the die-swell of the bead as it exits the nozzle, in turn leading to less inter-laminar gaps during processing (Figure 16(e) \& (f)) [24]. However, the voids within the material can increase with at higher fiber loading (Figure 16(f), (g) \& (h)) [24]. Even though voids slightly increase as the percentage of fiber reinforcement increases, the strength also increases. The thought is that the increase of fibers increases bridging between deposited layers [93]. Fiber-filled printed composites 
show a tendency to have stronger material properties along the print direction, due to the fibers aligning while being forced through the print nozzle [16, 23, 24, 95].
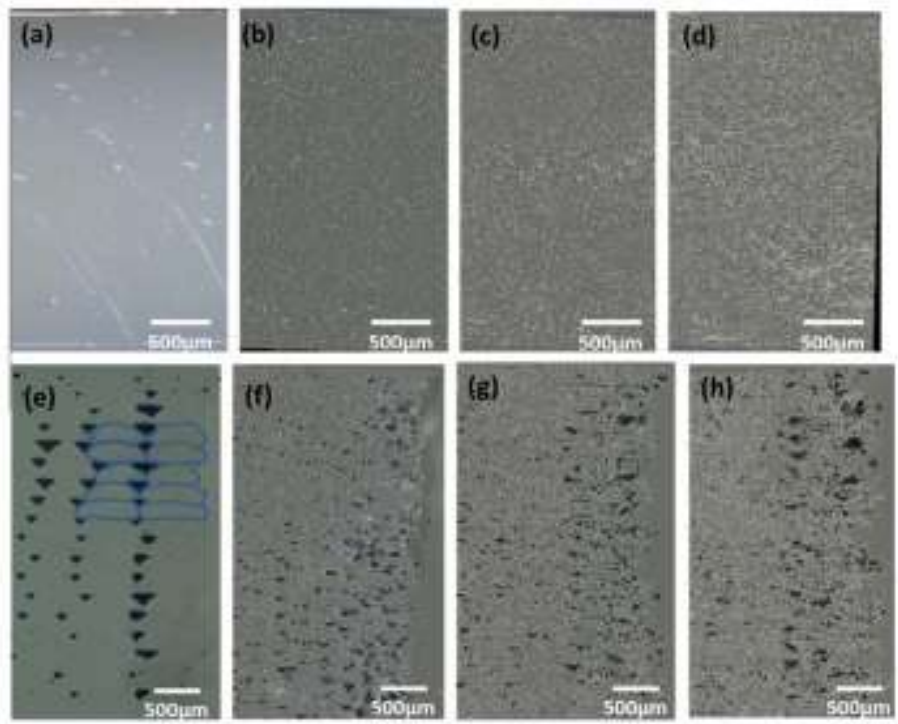

Figure 16: Comparison between compression molded (CM) composites and printed composites. a) CM dogbone with $0 \%$ carbon fiber (CF), b) $10 \% \mathrm{CF}$, c) $20 \% \mathrm{CF}$, d) $30 \% \mathrm{CF}$. e) a printed thermoplastic dogbone with 0\% CF, f) $10 \% \mathrm{CF}, \mathrm{g}) 20 \% \mathrm{CF}$ and h) $30 \% \mathrm{CF}[24]$

Another downfall of material extrusion fiber reinforced parts is a poor interface between the matrix and the small-scale fibers, which lowers the strength of the material due to fiber pullout $[23,93]$. Figure 17 is an image of vapor grown carbon fiber (VGCF)-doped ABS filament that was created by Shofner et al [23]. The fibers are highly aligned in the axial direction, indicated by the double headed arrow in the image. Poor fiber/matrix adhesion from poor wetting of the fibers is also observed. The fibers are clean and the surface of the polymer does not show damage around the fibers, indicating a high level of fiber pullout. Even with these defects in the extruded filament, the VGCF-doped ABS had higher strength ( $35 \mathrm{MPa})$ than the un-doped specimen ( 25 MPa) [23]. 


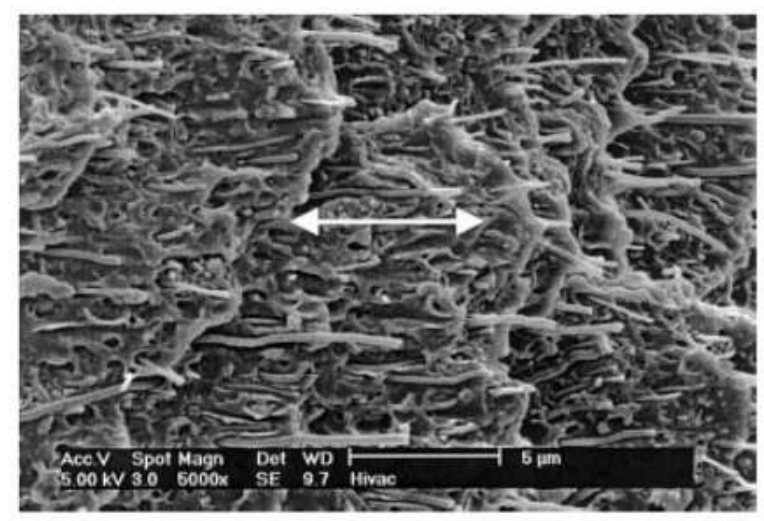

Figure 17: VGCF extruded via MATERIAL EXTRUSION aligned along the print direction, with a high concentration of voids verifying poor interfacial properties [23]

Ning et al. found that adding carbon fiber into thermoplastic filament lead to higher tensile strength and greater Young's modulus, but decreased toughness, yield strength, and ductility. In these studies, $5 \mathrm{wt} \%$ carbon fiber had the highest tensile strength, flexural stress, flexural modulus, and flexural toughness [96]. Samples consisting of $7.5 \mathrm{wt} \%$ had the highest Young's modulus. Higher weight percentages experienced issues with porosity which led to poor mechanical properties [97].

In later studies comparing processing conditions, it was determined that having a raster angle of $[0,90]$ provides higher tensile strength, Young's modulus, and yield strength than raster angles of $[45,-45]$. Higher infill speeds led to less interaction and bonding between printed paths giving lower mechanical properties, and thinner layers decreased the number of voids and increased the tensile properties. Finally, a nozzle temperature of $220^{\circ} \mathrm{C}$ allowed for well-bonded interlayers, and thus gave the best properties overall. Higher temperatures yielded pores within the samples which caused lower tensile properties [98].

One of the advantages that additive manufacturing has over traditional composite manufacturing is the ability to create preforms with greater complexity, without the added 
effort. This is demonstrated by a study by Quan et al. in 3D composite preforms [99], in which chopped carbon fiber and ABS were used to create preforms that were infused with silicon to create high strength composites. However, this study again demonstrated the potential complexity of printing composites, the poor interfacial bonding between matrix and reinforcement $[99,100]$.

\subsubsection{Thermoset Material Extrusion}

Thermoset resins have been used in material extrusion systems to create fiber reinforced composite specimens in a process previously titled solid freeform fabrication which is now referred to as a branch of material extrusion by ASTM F2792 standards [16, 101, 102]. The most common method of accomplishing a thermoset print ink is by additives such as nanoclay particles or silica which are added to make the resin into a viscoelastic fluid that holds its shape upon printing $[16,101]$. The resin was diluted with dioxane (a solvent), with the expectation that after printing on a $100^{\circ} \mathrm{C}$ hotplate, the dioxane would evaporate and create a hardened part that could then be moved to the oven to cure overnight at $100^{\circ} \mathrm{C}[103]$. By altering epoxy resin using additives to create a thixotropic material that thins during extrusion through the nozzle, layers of reinforced resin were produced that were able to maintain shape throughout the curing cycle. The curing process takes place in a heated oven for 15 hours for the composite to cure completely, and is then allowed to cool for 2 hours before removing. The extruded fiber doped ink typically shows fiber alignment, so long as the extrusion rate of the slurry is greater than or equal to the print speed [101, 102]. It was found that the higher the pump speed compared to the write speed, the more oriented the fibers became [102]. 
Compton et al. [16], used this method to create cellular composites to mimic the performance of balsa wood. The printer ink has a pot life of 30 days, which allows for the printing and the curing process to take place separately. Separating these processes allows layers to merge during the printing process, yielding better bonding between layers. The alignment of the fibers during the extrusion process also allows spatial orientation of the reinforcement during printing, giving strength along the print direction. This capability to align reinforcement allows for the potential to spatially optimize the strength of an engineering design [16]. Nozzle size has no notable influence on this orientation when tested with nozzles between 200-610 $\mu \mathrm{m}$ [16].

Figure 18 and Figure 19 show the fracture surface of an epoxy ink printed composite $[16,101]$. The fibers are oriented in the same direction, and fiber pull out and voids can be seen throughout the fracture surface. The strength of printed composites using the epoxy ink method have yet to reach the full strength of typical epoxy composites. This is possibly because of the poor wettability of the fibers, and the increase of voids caused by the printing process $[16,101]$. The boundaries between consecutive layers are unnoticeable in both figures, showing that the deposited layers fully coalesce, strengthening the composites.

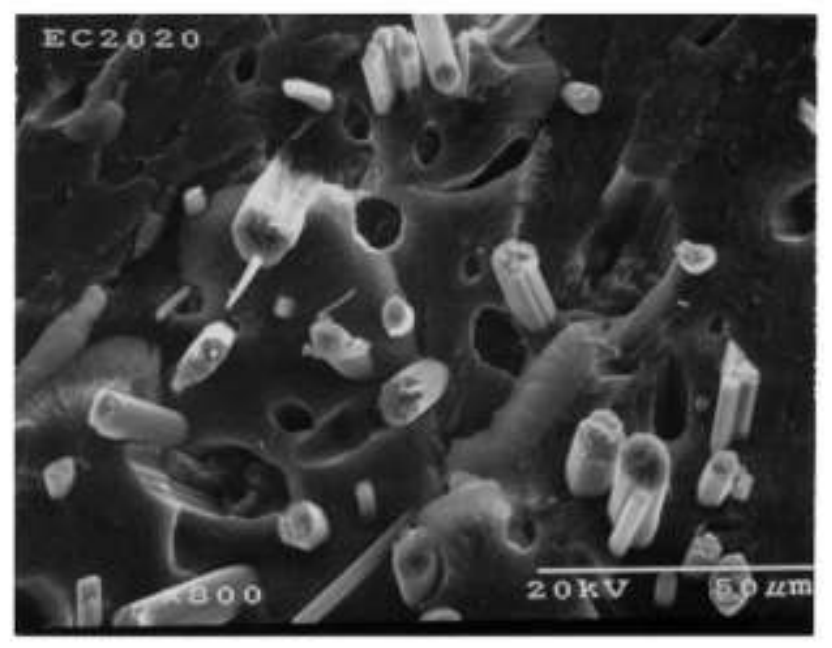



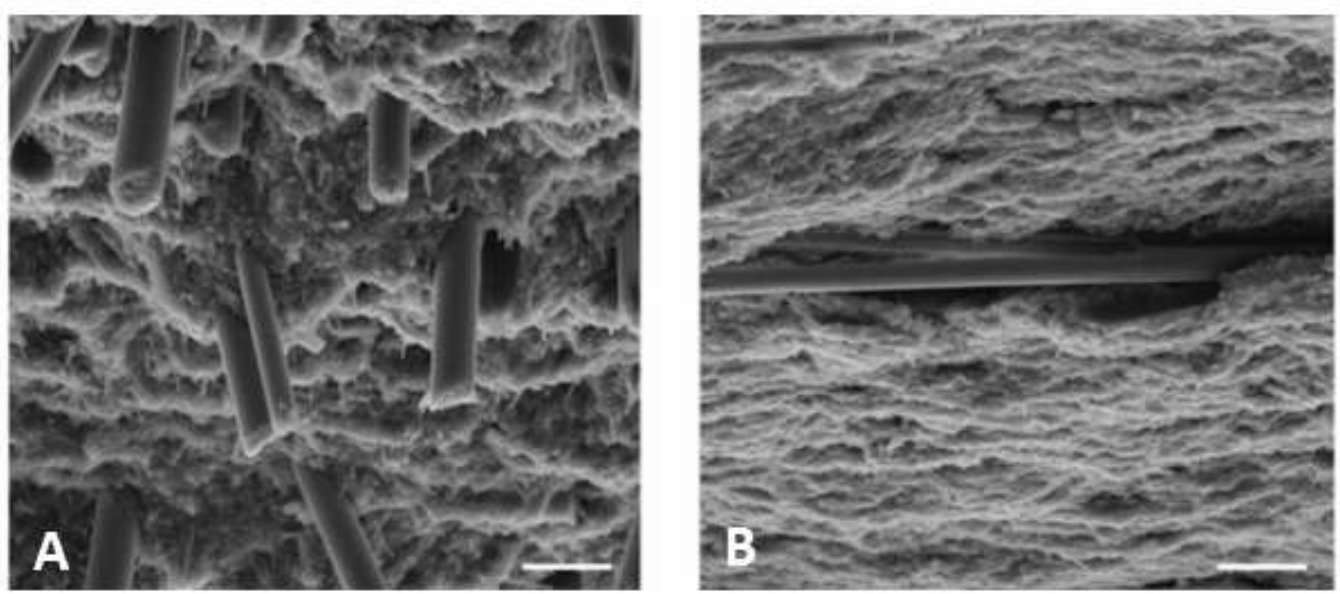

Figure 19: Extruded thermoset composite also shows propensity to fibers aligning along print direction a) shows the surface perpendicular to print, and b) shows the surface parallel to the print direction [16]

Current research trends are looking into the ability to orient fibers within the extrusion process in a direction that differs from the print direction. Holmes et al. [104] manipulated nanofillers such as aluminum using their Field-Aided Laminar Composite system (FALCom). FALCom works by using electric fields to align and orient particles within a polymer system during the printing process [104]. Collino et al. [105] demonstrated acoustic-field-assisted deposition of composites created from a shear thinning epoxy ink, combined with $\mathrm{SiC}$ fibers, glass, and $\mathrm{BaTiO}_{3}$ microspheres. This method allowed for higher volume fractions compared to other methods because of the ability to manipulate particles within a small stream during deposition. Kokkinis et al. [106], was able to magnetically orient alumina platelets in a soft composite in order to control the microstructure of printed soft composites. Adding this additional ability to change the microstructure of the composite during printing gives extended capability that is unattainable in traditional 
composite manufacturing methods, and allows for tailorable strength in multifunctional printed parts.

\subsubsection{Material Extrusion Summary}

The strength of composites printed with material extrusion is summarized in Figure 20 and tabulated in Table 2. It can be noted from Figure 20, with few exceptions, the tensile strength of thermoset material extrusion has only reached between $20 \%-75 \%$ that of a typical chopped glass or carbon fiber composite. The reasoning behind this could range from use of discontinuous fibers to poor interfacial strength between the matrix and fiber or poor interlayer bonding during printing. The highest elastic modulus thus far for chopped

fiber composites is by Compton et al. [16] at 24.54 GPa. This could be due to the high fiber volume content at $34.8 \%$, which is also the highest up to now for this method. Crockett et al. created the strongest composite with a carbon fiber-PEEK composite with $30 \%$ fiber volume; low void content is expected to have contributed to their success [95]. The use of single walled carbon nanotubes and VGCF in a printed polymer composite had the lowest strength and modulus because of poor interfacial properties, and considerable voids and pullout [94]. 


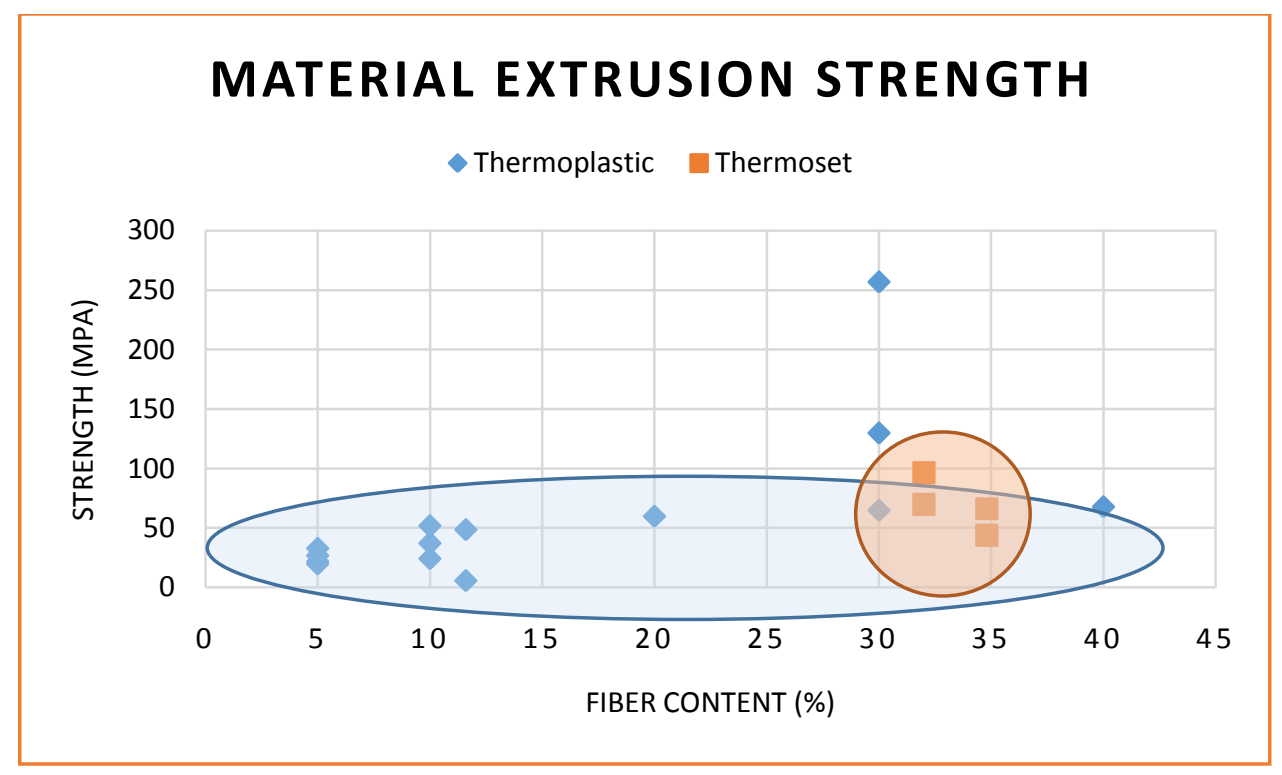

Figure 20: Distribution of strength of composites printed with material extrusion

Table 2 Material Properties of Composites Printed Using Material Extrusion

\begin{tabular}{|c|c|c|c|c|c|c|}
\hline Material & $\begin{array}{l}\text { Test } \\
\text { (Standards) }\end{array}$ & $\begin{array}{l}\text { Fiber } \\
\text { Content } \\
(\%)\end{array}$ & $\begin{array}{l}\text { Orientation to } \\
\text { print direction } \\
\text { (degrees) }\end{array}$ & $\begin{array}{l}\text { Young's } \\
\text { Modulus } \\
\text { (GPa) }\end{array}$ & $\begin{array}{l}\text { Strength } \\
\text { (MPa) }\end{array}$ & Ref. \\
\hline \multirow{4}{*}{$\begin{array}{l}\text { Carbon Fiber- } \\
\text { ABS }\end{array}$} & \multirow{4}{*}{$\begin{array}{l}\text { Tensile } \\
\text { (ASTM D638 } \\
\text { type-V) }\end{array}$} & 10 & 0 & $\sim 8$ & $\sim 52$ & \multirow[t]{4}{*}{ [24] } \\
\hline & & 20 & 0 & $\sim 11$ & $\sim 60$ & \\
\hline & & 30 & 0 & $\sim 14$ & $\sim 65$ & \\
\hline & & 40 & 0 & $\sim 14$ & $\sim 68$ & \\
\hline \multirow[t]{2}{*}{ SWNT-ABS } & $\begin{array}{l}\text { Tensile } \\
\text { (ASTM D638 } \\
\text { Type V) }\end{array}$ & \multirow[t]{2}{*}{5} & \multirow[t]{2}{*}{ NA } & $\sim 0.3$ & $\sim 22$ & \multirow[t]{2}{*}{ [94] } \\
\hline & $\begin{array}{l}\text { Tensile } \\
\text { (Fiber) }\end{array}$ & & & $\sim 1.75$ & $\sim 33$ & \\
\hline \multirow[t]{2}{*}{ VGCF-ABS } & $\begin{array}{l}\text { Tensile } \\
\text { (ASTM D638 } \\
\text { Type V) }\end{array}$ & \multirow[t]{2}{*}{5} & \multirow[t]{2}{*}{ NA } & $\sim 0.25$ & $\sim 20$ & \multirow[t]{2}{*}{ [94] } \\
\hline & $\begin{array}{l}\text { Tensile } \\
\text { (Fiber) }\end{array}$ & & & $\sim 1.3$ & $\sim 27$ & \\
\hline \multirow[t]{2}{*}{ VGCF-ABS } & $\begin{array}{l}\text { Tensile } \\
\text { (ASTM D638 } \\
\text { Type V) }\end{array}$ & 10 & 0 & 0.79 & 37.4 & \multirow[t]{2}{*}{ [23] } \\
\hline & $\begin{array}{l}\text { Tensile } \\
\text { (dogbone) }\end{array}$ & 10 & $10 / 90$ & NA & 24.4 & \\
\hline $\begin{array}{l}\text { Glass fiber- } \\
\text { ABS-LLDPE- }\end{array}$ & $\begin{array}{l}\text { Tensile } \\
\text { (none-printed }\end{array}$ & $10.2-13$ & 0 & NA & $\begin{array}{l}38.93- \\
58.60\end{array}$ & [93] \\
\hline
\end{tabular}




\begin{tabular}{|c|c|c|c|c|c|c|}
\hline $\mathbf{P E}$ & $\begin{array}{l}\text { square } \\
\text { frames) }\end{array}$ & & 90 & NA & $\begin{array}{l}0.72- \\
11.15\end{array}$ & \\
\hline \multirow{2}{*}{$\begin{array}{l}\text { Silicon Carbide } \\
\text { whiskers - } \\
\text { Epoxy }\end{array}$} & \multirow{2}{*}{$\begin{array}{l}\text { Tensile } \\
\text { (tensile bar- } \\
\text { none) }\end{array}$} & 32 & 0 & 16.10 & 96.6 & \multirow[t]{5}{*}{ [16] } \\
\hline & & 32 & 90 & 10.61 & 69.8 & \\
\hline \multirow{3}{*}{$\begin{array}{l}\text { Carbon } \\
\text { fiber/Silicon } \\
\text { carbide } \\
\text { whiskers - } \\
\text { Epoxy }\end{array}$} & \multirow{3}{*}{$\begin{array}{l}\text { Tensile } \\
\text { (tensile bar- } \\
\text { none) }\end{array}$} & 34.8 & 0 & 24.54 & 66.2 & \\
\hline & & & & & & \\
\hline & & 34.8 & 90 & 8.06 & 43.9 & \\
\hline \multirow{2}{*}{$\begin{array}{l}\text { Carbon fiber - } \\
\text { PEEK }\end{array}$} & \multirow{2}{*}{$\begin{array}{l}\text { Tensile } \\
\text { (ASTM } \\
\text { D638) }\end{array}$} & 30 & 0 & 9.4 & 257 & \multirow[t]{4}{*}{ [95] } \\
\hline & & 30 & 90 & 3.6 & 124 & \\
\hline \multirow{2}{*}{$\begin{array}{l}\text { Glass fiber - } \\
\text { Polycarbonate }\end{array}$} & \multirow{2}{*}{$\begin{array}{l}\text { Tensile } \\
\text { (ASTM } \\
\text { D638) }\end{array}$} & 30 & 0 & 7 & 130 & \\
\hline & & 30 & 90 & 7 & 130 & \\
\hline $\begin{array}{l}* \text { Carbon fiber } \\
\text { reinforced-PLA }\end{array}$ & $\begin{array}{l}\text { Tensile } \\
\text { (dogbone) }\end{array}$ & 1 & 0 & 5.8 & 90.0 & [87] \\
\hline $\begin{array}{l}\text { Continuous } \\
\text { Carbon Fiber - } \\
\text { Nylon }\end{array}$ & $\begin{array}{l}\text { Tensile } \\
\text { (tensile bar) }\end{array}$ & 34.5 & 0 & 35.7 & 466.4 & [88] \\
\hline
\end{tabular}

\subsection{Sheet Lamination}

Most notably used for creating objects using sheets of fused paper or plastic, sheet lamination is one of the quickest additive manufacturing methods to create a composite part. Sheet lamination is useful when creating parts from prepreg sheets. The process consists of a machine that deposits the sheets and then heats, compresses, and cuts the layers to form a single part $[25,107,108]$. Sheet lamination is able to embed wires into the layers during manufacturing [65]. Tension tests of fiber reinforced specimens showed that the ultimate strength was $70 \%$ that of the manufacturer's supplied ultimate tensile strength for the material, thus highlighting a problem in creating the samples that leads to parasitic properties [108]. There are specific methods that allow fabrication of curved parts, reducing waste by utilizing a curved mandrel surface during the print process [25]. A curved mandrel 
reduces stress concentrations in the composite, because fiber continuity is kept throughout the process $[25,109]$. Curing of the composite parts usually requires another step, as sheet lamination machines are unable to provide the heat and pressure needed for a full cure [108].

Sheet lamination creates composites from laminated prepreg sheets of fiber reinforced polymers, making it the most similar to stacking by dry preforms. The material it uses must be in a sheet form that can be rolled, pressed, and cut as required. The issues exhibited when making composites pressed during fabrication are: (1) shrinkage, (2) warping, (3) delamination, and (4) shape deformation. The pressing process helps by creating parts that are comparable to that made by conventional processes and have a void content below $5 \%$ (compared to the $2 \%$ rule of thumb for conventionally manufactured composites) [108].

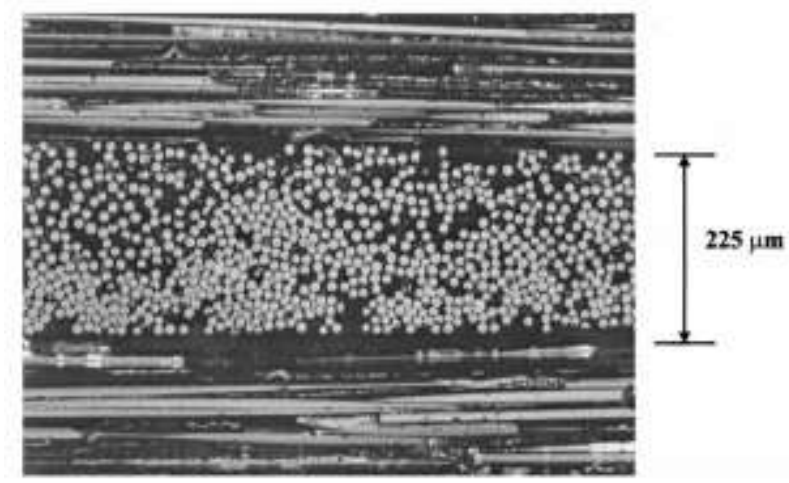

Figure 21: Composite layers at $0^{\circ}$ and $90^{\circ}$, created by LOM [108]

Figure 21 shows a micrograph of a unidirectional composite formed by sheet lamination. The smooth surface is indicative of a well-bonded composite and is similar to failure modes seen in traditionally processed composites [110]. Table 3 details the results of composite production using sheet lamination technology.

Table 3 LOM composite material properties 


\begin{tabular}{|c|c|c|c|c|c|c|}
\hline Material & $\begin{array}{l}\text { Test } \\
\text { (Standards) }\end{array}$ & $\begin{array}{l}\text { Fiber } \\
\text { Content } \\
(\%)\end{array}$ & Orientation & $\begin{array}{l}\text { Young's } \\
\text { Modulus } \\
\text { (GPa) }\end{array}$ & $\begin{array}{l}\text { Strength } \\
\text { (MPa) }\end{array}$ & Ref. \\
\hline \multirow[t]{4}{*}{$\begin{array}{l}\text { Glass Fiber- } \\
\text { Epoxy }\end{array}$} & $\begin{array}{l}\text { Tension } \\
\text { (ASTM-D- } \\
\text { 3039) }\end{array}$ & 55 & 0 & NA & 713 & \multirow[t]{4}{*}{ [108] } \\
\hline & $\begin{array}{l}\text { Compression } \\
\text { (ASTM-D- } \\
695 \text { ) }\end{array}$ & 55 & 0 & NA & 896 & \\
\hline & $\begin{array}{l}\text { Flexure } \\
\text { (ASTM-D- } \\
790)\end{array}$ & 55 & 0 & NA & 1190 & \\
\hline & $\begin{array}{l}\text { Interlaminar } \\
\text { shear } \\
\text { (ASTM D- } \\
\text { 2344) }\end{array}$ & 55 & $0 / 90$ & NA & 42.6 & \\
\hline
\end{tabular}

\subsection{Powder Bed Fusion (PBF)}

Powder-based systems have the unique attribute of being able to manufacture plastics, polymers and metal parts. In powder bed fusion (PBF), a laser beam is used to consolidate powder together to form a layer. The build platform moves downward the thickness of one layer, and powder is spread over the sintered layer. The chamber where the powder is kept is typically kept at a temperature just below the melting point of the material for plastic parts, so the laser needs to heat the material only slightly to initiate melting [13]. Typically, this method of creating parts is useful because of its ability to use a mixture of powders to create a new hybrid or composite material, for example metal matrix, ceramic matrix, and polymer blends $[111,112]$. J.P. Kruth et al. proposed a method of distinguishing the different ways that powders can be fused together. The 4 main ways cited are solid state sintering, chemically induced binding, liquid phase sintering partial melting and full melting [113]. 
In solid state sintering, the material is fused together by neck formation between particles. The parts formed by powder bed fusion usually have high material properties because the material is fused together by heat. Chemically induced binding is caused from the laser disintegrating the material, which then causes the bonding between particles, as with $\mathrm{SiC}$ ceramics. For composite systems formed by PBF, the most likely form of consolidation would come from liquid phase sintering, where one material remains solid during processing while the matrix material liquefies to become the binder. No supports are needed to during the creation of parts because of the powders' ability to support overhanging structures during manufacturing, requiring less material for parts with many overhangs. However, a major drawback of this method is the energy cost of keeping the material just below melting temperature for the duration of manufacturing. Cavities within parts can be filled with un-sintered powder during fabrication, harming composite properties. Additionally, sanding, lacquering, painting or other post processing procedures must be performed to get a good finish, due to the grittiness of powder-based parts [66].

PBF is being used for fiber reinforced composite fabrication to create small projects like unmanned aerial vehicles [114]. Typically, the reinforcement fibers are mixed with the powdered matrix material. The laser sinters together the material, and post processing is performed. Post processing can consist of first placing the part in an oven to convert binders, and then infilling the part with resin to further strengthen the composite and reduce voids [56]. 
Table 4 PBF composite material properties

\begin{tabular}{|c|c|c|c|c|c|c|}
\hline Material & $\begin{array}{l}\text { Test } \\
\text { (Standards) }\end{array}$ & $\begin{array}{l}\text { Fiber } \\
\text { Content } \\
(\%)\end{array}$ & $\begin{array}{l}\text { Orientation to } \\
\text { print direction }\end{array}$ & $\begin{array}{l}\text { Modulus } \\
\text { (GPa) }\end{array}$ & $\begin{array}{l}\text { Strength } \\
\text { (MPa) }\end{array}$ & Ref. \\
\hline \multirow[t]{2}{*}{$\begin{array}{l}\text { Glass fiber - } \\
\text { Polyamide } 12\end{array}$} & $\begin{array}{l}\text { Fatigue @ } \\
23^{\circ} \mathrm{C} \\
\text { (ASTM } \\
\text { E647) }\end{array}$ & 25 & $\mathrm{y}$-z plane & 2.71 & 43.7 & \multirow[t]{2}{*}[21]{} \\
\hline & $\begin{array}{l}\text { Fatigue @ - } \\
50^{\circ} \mathrm{C} \\
\text { (ASTM } \\
\text { E647) }\end{array}$ & 25 & $\mathrm{y}$-z plane & 6.6 & 73 & \\
\hline \multirow{2}{*}{$\begin{array}{l}\text { Carbon } \\
\text { Fiber- } \\
\text { Polyamide } 12\end{array}$} & \multirow{2}{*}{$\begin{array}{l}\text { Tensile } \\
\text { (ASTM } \\
\text { D3039) }\end{array}$} & \multirow[t]{2}{*}{ NA } & \multirow[t]{2}{*}{ NA } & $\mathrm{E}_{\mathrm{x}}=6.3$ & \multirow[t]{2}{*}{ NA } & \multirow[t]{2}{*}[22]{} \\
\hline & & & & $\begin{array}{l}E_{y}=3.54 \\
E_{z}=2.70\end{array}$ & & \\
\hline \multirow{3}{*}{$\begin{array}{l}\text { Carbon } \\
\text { fiber- } \\
\text { polyamide } 12 \\
\text { (surface } \\
\text { treatment) }\end{array}$} & \multirow{3}{*}{$\begin{array}{l}\text { Flexural } \\
\text { (ISO178- } \\
1993(E))\end{array}$} & 30 & 0 & $\sim 2.7$ & $\sim 75$ & \multirow[t]{3}{*}{ [115] } \\
\hline & & 40 & 0 & $\sim 3.2$ & $\sim 95$ & \\
\hline & & 40 & 0 & $\sim 4.75$ & $\sim 115$ & \\
\hline
\end{tabular}

Glass fiber reinforced composite materials made by 3D Systems have been tested using ASTM standard E647 [21]. It was found that the fibers were effective in stopping crack propagation during fatigue testing and the mode of failure for these composites was weak interfacial bonding. The Young's modulus and tensile strength were slightly higher than that of non-reinforced ABS processed by injection molding $(E=1.72 \mathrm{GPA}, \sigma=45.1 \mathrm{MPa})$, as shown in Table 4 [21]. After this infiltration, the part is cured at $80^{\circ} \mathrm{C}$ for 1 hour. The inclusion of fibers leads to problems with consolidation of the polymer [116]. 

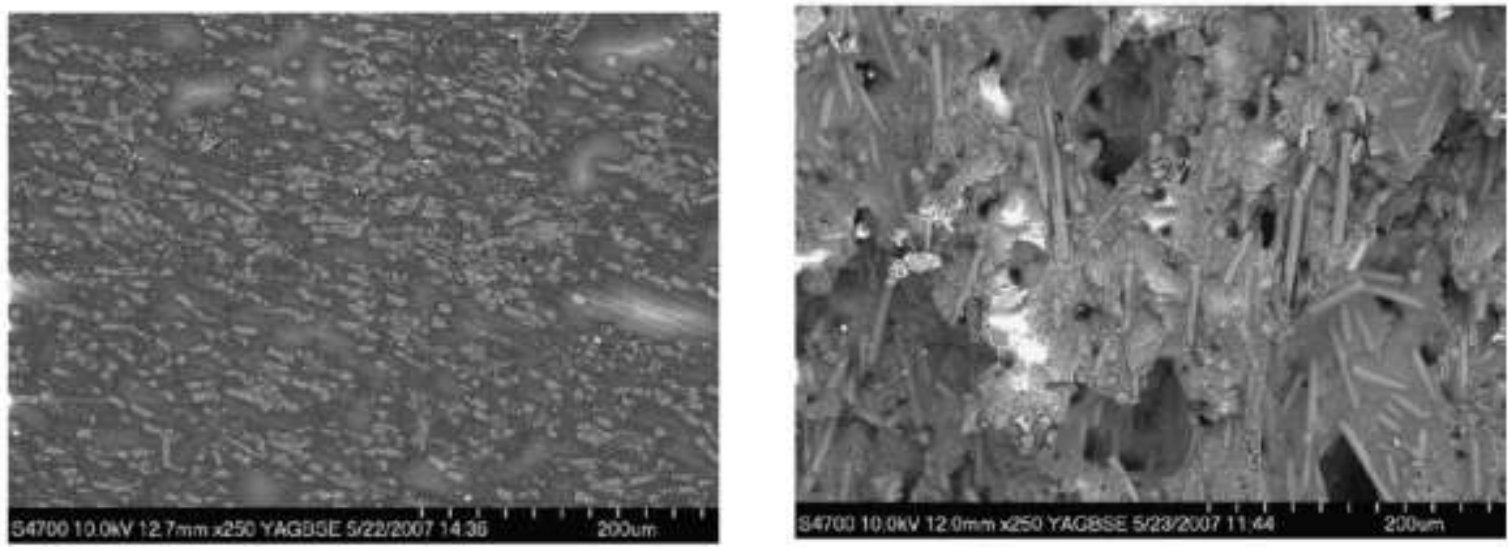

Figure 22: Alignment of fibers in the A) xz plane and the B) $x y$ plane [22]

PBF carbon fiber reinforced composites were tested for tensile modulus following ASTM standard D3039 [22]. The created composite was an orthotropic material, seen by the visible alignment of the fibers in the xy plane (Figure 22 (A) \& (B)). However, these composites showed significant fiber pull out and breakage during testing, indicative of poor interfacial properties [110]. Flexural tests done as per standard ISO178-1993(E) with carbon fiber reinforced polyamide-12 found enhanced flexural strength and modulus [115]. The fracture surface of the specimen, seen in Figure 23, shows matrix deformation occurred as well as tensile fracture of the fibers, indicating good interfacial bonding between the matrix and the fiber reinforcement [110]. This is similar to the properties observed in injection molded composites of similar composition. Furthermore, by treating the fibers with oxidation, a greater interfacial bond was created between the polymer and the fiber, leading to increased strength [115]. By coating the fibers with polymer using chemical precipitation before PBF, the wettability of the composite increased due to higher interfacial properties [115]. 

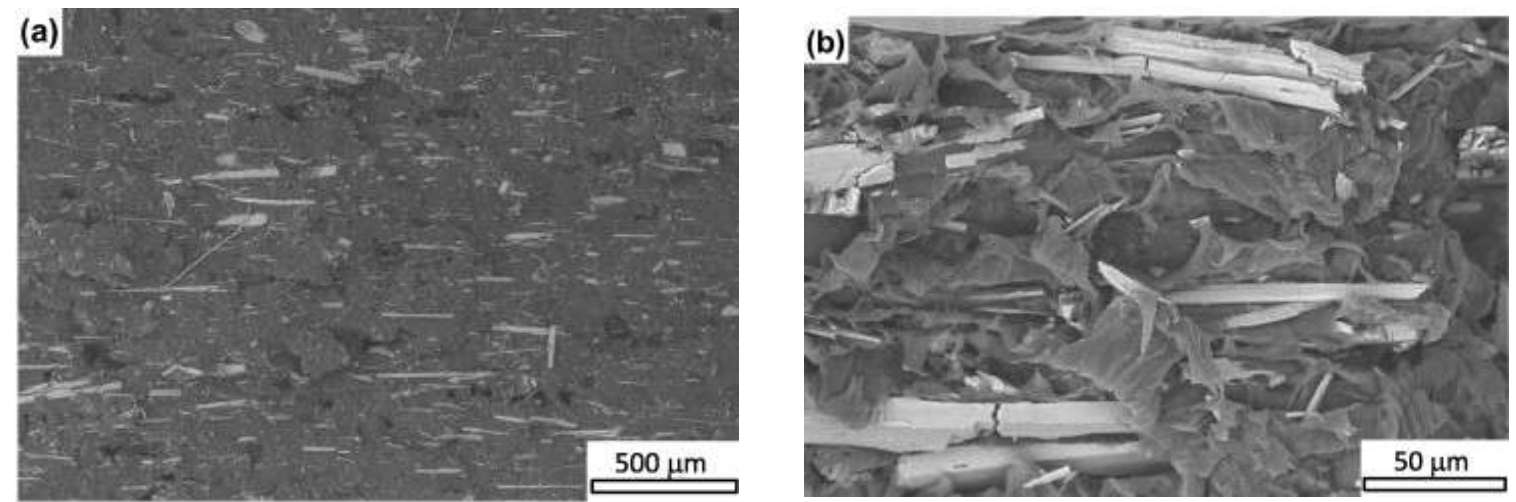

Figure 23: Fracture surface of fiber reinforced PA-12 a) panoramic view b) view of fiber bridging and pullout along with matrix deformation [21]

\section{CONCLUSION}

There is a need to quickly produce high quality composite parts in a cost effective manner. While AFP, ATL, and FW all have the capabilities of quickly creating parts accurately, the expense in buying the necessary specialized equipment often keeps these technologies out of the reach of small-to-medium manufacturers. Additive manufacturing has the ability to quickly transverse from idea to part without the waste in material, tooling, and time seen in the automated methods. Parts can be customized for a number of applications and this can occur as quickly as needed, which makes the technology ideal for prototyping and individualization. Current methods for composite AM have the capability of producing strong parts, but full capability has yet to be realized with current systems. Sheet lamination, for example, has the ability to create parts out of woven composite material that is pre-impregnated with resin, but as of yet has not been used in an industrial setting.

Figure 24 and Figure 25 compare the modulus and strength for the different additive manufacturing methods. Overall, material extrusion is used most often, whereas sheet 
lamination exhibits the best quality composites. As shown in Figure 24, composites made with material extrusion along the print direction had the highest modulus thus providing the ability to tailor stiffness in specific directions. Figure 24 also shows a corresponding lack of stiffness in the direction transverse of printing for material extrusion composites as seen in material extrusion $90^{\circ}$ data points. This is probably due to the weakness along the layered direction of a print, where boundaries between layers yield voids and discontinuities. In terms of fiber percentage, the highest fiber volumes are achieved using material extrusion and PBF, where the percentage of reinforcement loading is not limited due to the process. PBF does not yet have the Young's modulus achieved by material extrusion due to limitations with voids during the sintering process.

The strength of printed fiber reinforced composites does not have such clear delineations as does the elasticity, but material extrusion does have the highest strength of the different methodologies, as seen in Figure 25. This may be due to the higher loading percentages of chopped fiber within these printed composites. The direction of force versus the direction of print does not show much of a difference in strength due to poor interfacial properties between the matrix and reinforcement material and fiber pullout (which leads to low load transfer to the fiber component of the composite). 


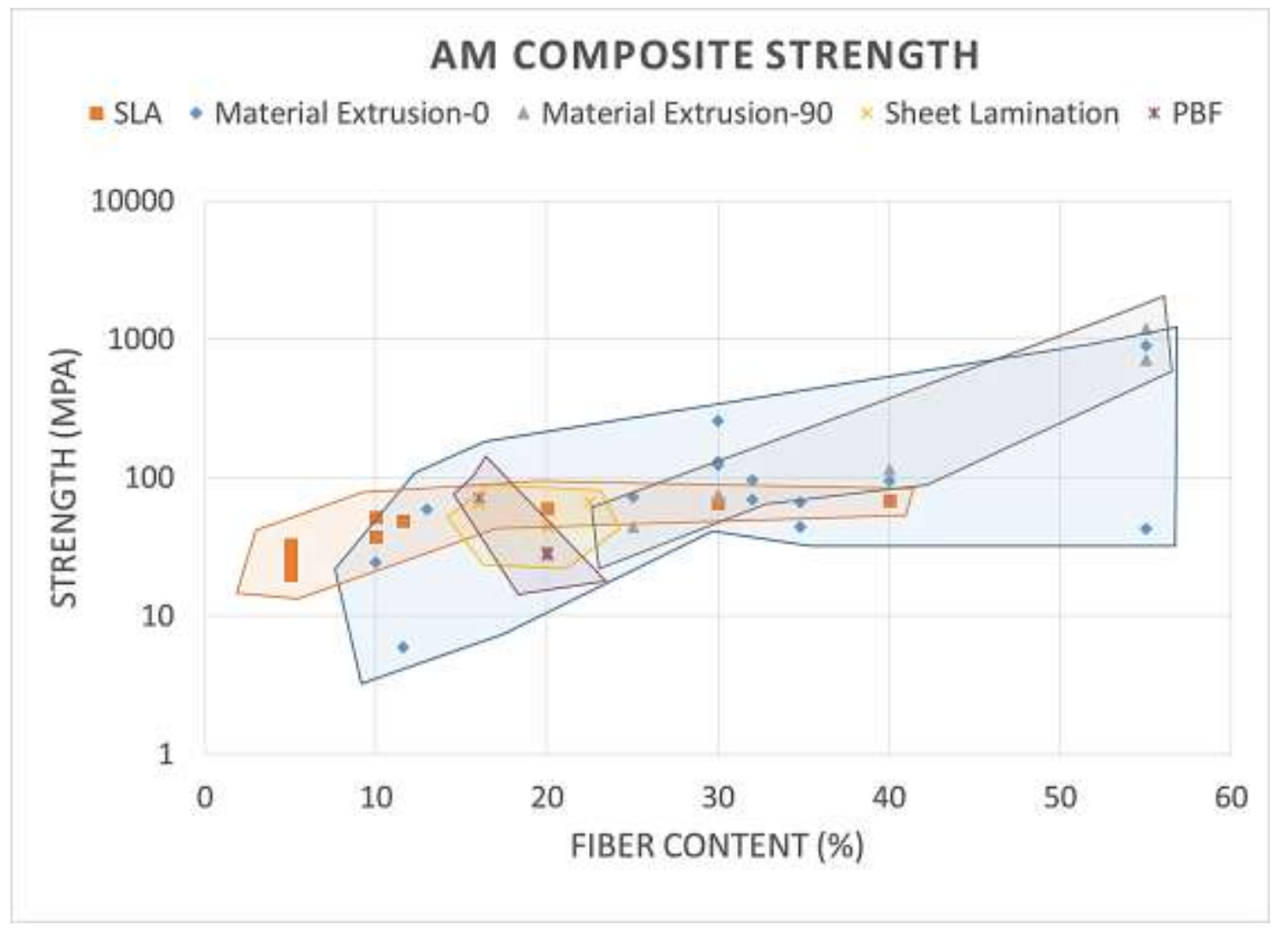

Figure 24: Modulus of composites made from AM technology 


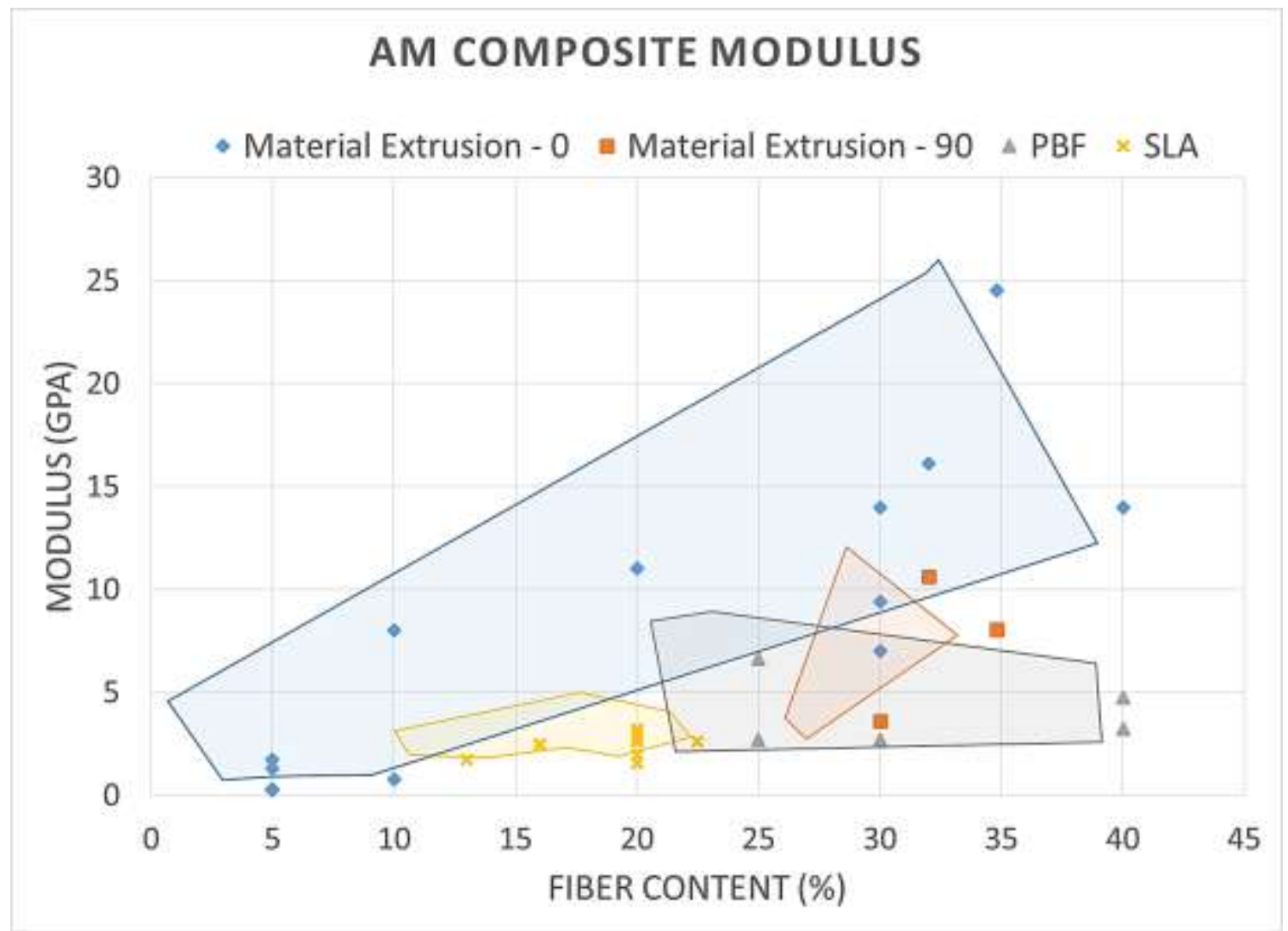

Figure 25: Strength of Composites made from AM technology

Compared to traditional manufacturing, AM has the ability to create composites with shorter cycle times and less waste due to near net shape printing. Current trends in composite additive manufacturing are moving towards the ability to include continuous fiber as a filament, in order to obtain material properties that are comparable with traditional manufacturing methods. Also, the ability to reorient the reinforcing material during the printing process is currently gaining traction due to its ability to customize part strength. AM contains the capacity to create a fully optimized product, with the ability to align fibers multiple ways as well as control the fiber volume throughout the part processes that would be unfeasible with traditional composite manufacturing methods. The technology is able to create customizable products without having to invest in tooling for 
each product iteration. However, to compete with the strength of traditional methods, interfacial properties must be better understood. In the future, the difference between parts made with traditional composite manufacturing technology and AM will continue to decrease. The merging of the manufacturing methods will yield higher quality parts, with more customization and less cost and variability in the manufactured part.

\section{ACKNOWLEDGEMENTS}

J. Frketic is supported by the Florida State University Adelaide Wilson graduate fellowship. S. Ramakrishnan was supported by AMSRD-ARLRO-SI proposal number: 62885-MS-REP, agreement number: W911NF-13-1-0132 from the Department of Defense (Army Research Office). 


\section{REFERENCES}

[1] Heavy metal: Three-dimensional printing may help entrench the world's engineering giants, The Economist, Berlin, 2014.

[2] M. LaMonica, 3-D Printing Will Soon Become a Routine Manufacturing Tool | MIT Technology Review, Technology Review, 2015.

[3] ORNL Revealed the 3D-Printed Shelby Cobra, 2015. http://web.ornl.gov/sci/manufacturing/media/news/detroit-show/index.shtml.

[4] O.R.N. Laboratory. http://www.ornl.gov/.

[5] P. Zelinski, IMTS's 3D Printed Car Will Be Made of Carbon-Fiber-Filled Plastic, 2014. http://www.mmsonline.com/blog/post/imtss-3d-printed-car-will-be-made-of-carbon-fiber-filled-

plastic.

[6] J.E. Lindbäck, A. Björnsson, K. Johansen, New Automated Composite Manufacturing Process:: Is it possible to find a cost effective manufacturing method with the use of robotic equipment?, Proceedings of the 5th International Swedish Production Symposium, 2012, pp. 523-531.

[7] ATL \& AFP: Defining the megatrends in composite aerostructures, High Performance Composites 16(4) (2008) 68-71.

[8] A. Mafeld, The Automation of Polymer Composites Manufacturing, Creaprod, Paris, France, 2010.

[9] M.N. Grimshaw, J. Manuel, L. Diaz, ADVANCED TECHNOLOGY TAPE LAYING FOR AFFORDABLE MANUFACTURING OF LARGE COMPOSITE STRUCTURES.

[10] M.L. Skinner, Trends, advances and innovations in filament winding, Reinforced Plastics (2006).

[11] F.P.W. Melchels, J. Feijen, D.W. Grijpma, A review on stereolithography and its applications in biomedical engineering, Biomaterials (2010).

[12] H. Lin, D. Zhang, P.G. Alexander, G. Yang, J. Tan, Application of visible light-based projection stereolithography for live cell-scaffold fabrication with designed architecture, Biomaterials (2013).

[13] A. Mazzoli, Selective laser sintering in biomedical engineering, Medical \& biological engineering \& computing (2013).

[14] L.S. Dimas, M.J. Buehler, Modeling and additive manufacturing of bio-inspired composites with tunable fracture mechanical properties, Soft Matter 10(25) (2014) 4436-4442.

[15] S. Christ, M. Schnabel, E. Vorndran, J. Groll, U. Gbureck, Fiber reinforcement during 3D printing, Materials Letters 139 (2015) 165-168.

[16] B.G. Compton, J.A. Lewis, 3D-Printing of Lightweight Cellular Composites, Advanced Materials (2014).

[17] Stratasys. http://www.stratasys.com/.

[18] Fiberforge. http://www.fiberforge.com/.

[19] B.C. Kim, K. Potter, P.M. Weaver, Continuous tow shearing for manufacturing variable angle tow composites, Composites Part A: Applied Science and Manufacturing 43(8) (2012) 1347-1356.

[20] A. Angerer, C. Ehinger, A. Hoffmann, W. Reif, G. Reinhart, G. Strasser, Automated cutting and handling of carbon fiber fabrics in aerospace industries, Automation Science and Engineering (CASE), 2010 IEEE Conference on, 2010, pp. 861-866.

[21] A. Salazar, A. Rico, J. Rodríguez, J. Segurado Escudero, R. Seltzer, F. Martin de la Escalera Cutillas, Fatigue crack growth of SLS polyamide 12: Effect of reinforcement and temperature, Composites Part B: Engineering 59(0) (2014) 285-292.

[22] R.B. Floersheim, G. Hou, K. Firestone, CFPC material characteristics and SLS prototyping process, Rapid Prototyping Journal 15(5) (2009) 339-345. 
[23] M.L. Shofner, K. Lozano, F.J. Rodriguez-Macias, E.V. Barrera, Nanofiber-reinforced polymers prepared by fused deposition modeling, Journal of Applied Polymer Science 89(11) (2003) 30813090.

[24] H.L. Tekinalp, V. Kunc, G.M. Velez-Garcia, C.E. Duty, L.J. Love, A.K. Naskar, C.A. Blue, S. Ozcan, Highly oriented carbon fiber-polymer composites via additive manufacturing, Composites Science and Technology 105 (2014) 144-150.

[25] D. Klosterman, R.P. Chartoff, Curved layer LOM of ceramics and composites, Solid Freeform ... (1998).

[26] M.P. Groover, Automation, production systems, and computer-integrated manufacturing, Prentice Hall Press2007.

[27] D.H.J.A. Lukaszewicz, C. Ward, K.D. Potter, The engineering aspects of automated prepreg layup: History, present and future, Composites Part B: Engineering 43(3) (2012) 997-1009.

[28] C. Grant, Automated processes for composite aircraft structure, Industrial Robot: An International Journal (2006).

[29] C. Technics. http://www.cnctechnics.com/Technology.html.

[30] F.H. Abdalla, S.A. Mutasher, Y.A. Khalid, S.M. Sapuan, A.M.S. Hamouda, B.B. Sahari, M.M. Hamdan, Design and fabrication of low cost filament winding machine, Materials \& design 28(1) (2007) 234-239.

[31] C. Laval, CADWIND 2006 - 20 years of filament winding experience, Reinforced Plastics 50(2) (2006) 34-37.

[32] P.K. Mallick, Fiber-reinforced composites: materials, manufacturing, and design, CRC press1993.

[33] J. Fleischer, J. Schaedel, Joining automotive space frame structures by filament winding, CIRP Journal of Manufacturing Science and Technology 6(2) (2013) 98-101.

[34] J. Rousseau, D. Perreux, N. Verdière, The influence of winding patterns on the damage behaviour of filament-wound pipes, Composites Science and Technology 59(9) (1999) 1439-1449.

[35] J.T. Paul Jr, Method of making low-void filament wound structures, Google Patents, 1969.

[36] C.M. Hayes, E.J. Latos, J.L. Mclarty, Method of making self-lubricating filament wound tube, Google Patents, 1971.

[37] B. Williams, E. Shehata, S.H. Rizkalla, Filament-wound glass fiber reinforced polymer bridge deck modules, Journal of Composites for Construction 7(3) (2003) 266-273.

[38] W. Polini, L. Sorrentino, Influence of winding speed and winding trajectory on tension in robotized filament winding of full section parts, Composites Science and Technology 65(10) (2005) 1574-1581.

[39] A. Beakou, M. Cano, J.B. Le Cam, V. Verney, Modelling slit tape buckling during automated prepreg manufacturing: A local approach, Composite Structures 93(10) (2011) 2628-2635.

[40] W. Goldsworthy, Geodesic path length compensator for composite-tape placement method, Patent US 3810805.

[41] B.C. Kim, P.M. Weaver, K. Potter, Manufacturing characteristics of the continuous tow shearing method for manufacturing of variable angle tow composites, Composites Part A: Applied Science and Manufacturing 61(0) (2014) 141-151.

[42] S. Nagendra, K. Srinivas, D. Jonathan, V. Parthasarathy, Optimization of tow fiber paths for composite design, 36th Structures, Structural Dynamics and Materials Conference, American Institute of Aeronautics and Astronautics1995.

[43] mtorres, 2014. http://www.mtorres.com/.

[44] C. Grant, Composites automation: Trending smaller and robotic : CompositesWorld, High Performance Composites, 2014. 
[45] G. Marsh, Automating aerospace composites production with fibre placement, Reinforced Plastics 55(3) (2011) 32-37.

[46] Automated Dynamics, 2014. http://www.automateddynamics.com/.

[47] Accudyne Systems, Inc, 2014. http://www.accudyne.com/.

[48] Fiber Placement Robot - Coriolis Composites, (2014).

[49] Electroimpact, 2014. https://www.electroimpact.com/.

[50] Assyst Bullmer Composites, 2014. http://assystbullmer.co.uk/industries/composites/.

[51] T.G.P. Gutowski, Advanced composites manufacturing, John Wiley \& Sons1997.

[52] K.V. Wong, A. Hernandez, A review of additive manufacturing, ISRN Mechanical Engineering 2012 (2012).

[53] F.P.W. Melchels, M.A.N. Domingos, T.J. Klein, J. Malda, P.J. Bartolo, D.W. Hutmacher, Additive manufacturing of tissues and organs, Progress in Polymer Science 37(8) (2012) 1079-1104.

[54] G. Wurm, B. Tomancok, K. Holl, J. Trenkler, Prospective study on cranioplasty with individual carbon fiber reinforced polymere (CFRP) implants produced by means of stereolithography, Surgical Neurology 62(6) (2004) 510-521.

[55] C. Emmelmann, P. Sander, J. Kranz, E. Wycisk, Laser additive manufacturing and bionics: redefining lightweight design, Physics Procedia (2011).

[56] D.L. Bourell, M.C. Leu, K. Chakravarthy, N. Guo, K. Alayavalli, Graphite-based indirect laser sintered fuel cell bipolar plates containing carbon fiber additions, CIRP Annals-Manufacturing Technology 60(1) (2011) 275-278.

[57] W.H. Wai, RP in art and conceptual design, Rapid Prototyping Journal 7(4) (2001) 217-219.

[58] N. Oxman, Variable property rapid prototyping: Inspired by nature, where form is characterized by heterogeneous compositions, the paper presents a novel approach to layered manufacturing entitled variable property rapid prototyping, Virtual and Physical Prototyping 6(1) (2011) 3-31.

[59] S. Jokic, P. Novikov, S. Maggs, D. Sadan, S. Jin, C. Nan, Robotic positioning device for threedimensional printing, arXiv preprint arXiv:1406.3400 (2014).

[60] O.R.N. Laboratories, ORNL revealed the 3D printed Shelby Cobra, 2015. http://web.ornl.gov/sci/manufacturing/media/news/detroit-show/.

[61] D.D. Gu, W. Meiners, K. Wissenbach, R. Poprawe, Laser additive manufacturing of metallic components: materials, processes and mechanisms, International Materials Reviews 57(3) (2012) 133-164.

[62] S. Lim, R.A. Buswell, T.T. Le, S.A. Austin, A.G.F. Gibb, T. Thorpe, Developments in constructionscale additive manufacturing processes, Automation in Construction 21(0) (2012) 262-268.

[63] E. Atzeni, A. Salmi, Economics of additive manufacturing for end-usable metal parts, Int J Adv Manuf Technol 62(9-12) (2012) 1147-1155.

[64] J.P. Kruth, M.C. Leu, T. Nakagawa, Progress in Additive Manufacturing and Rapid Prototyping, CIRP Annals - Manufacturing Technology 47(2) (1998) 525-540.

[65] I. Gibson, D.W. Rosen, B. Stucker, Additive Manufacturing Technologies: Rapid Prototyping to Direct Digital Manufacturing, Springer Science + Business Media, New York, 2010.

[66] C.K. Chua, K.F. Leong, 3D printing and additive manufacturing: principles and applications, 4 ed., World Scientific2015.

[67] M. Haberer, G. Zak, C.B. Park, B. Benhabib, Design of a slot-coater-based layered-composites manufacturing system, Journal of manufacturing science and engineering 125(3) (2003) 564-576.

[68] A.M. Elliott, O.S. Ivanova, C.B. Williams, T.A. Campbell, Inkjet Printing of Quantum Dots in Photopolymer for Use in Additive Manufacturing of Nanocomposites, Advanced Engineering Materials 15(10) (2013) 903-907. 
[69] Y. Lu, G. Mapili, G. Suhali, S. Chen, K. Roy, A digital micro-mirror device-based system for the microfabrication of complex, spatially patterned tissue engineering scaffolds, Journal of Biomedical Materials Research Part A 77(2) (2006) 396-405.

[70] R. Liska, M. Schuster, R. Inführ, C. Turecek, C. Fritscher, V. Seidl, S. V., J. Stampfl, Photopolymers for rapid prototyping, Journal of Coatings Technology and Research 4(4) (2007) 505-510.

[71] J.R. Tumbleston, D. Shirvanyants, N. Ermoshkin, R. Janusziewicz, A.R. Johnson, D. Kelly, K. Chen, R. Pinschmidt, J.P. Rolland, A. Ermoshkin, E.T. Samulski, J.M. DeSimone, Continuous liquid interface production of 3D objects, Science 347(6228) (2015) 1349-1352.

[72] D.E. Karalekas, Study of the mechanical properties of nonwoven fibre mat reinforced photopolymers used in rapid prototyping, Materials \& Design 24(8) (2003) 665-670.

[73] C.M. Cheah, J.Y.H. Fuh, A.Y.C. Nee, L. Lu, Mechanical characteristics of fiber-filled photopolymer used in stereolithography, Rapid Prototyping Journal 5(3) (1999) 112-119.

[74] G. Zak, M. Haberer, C.B. Park, B. Benhabib, Mechanical properties of short-fibre layered composites: prediction and experiment, Rapid Prototyping Journal 6(2) (2000) 107-118.

[75] G. Zak, M.N. Sela, V. Yevko, C.B. Park, B. Benhabib, Layered-manufacturing of fiber-reinforced composites, Journal of manufacturing science and engineering 121(3) (1999) 448-456.

[76] T. Nakamoto, S. Kojima, Layered Thin Film Micro Parts Reinforced with Aligned Short Fibers in Laser Stereolithography by Applying Magnetic Field, Journal of Advanced Mechanical Design, Systems, and Manufacturing 6(6) (2012) 849-858.

[77] T. Vaneker, E. Hofland, Additive manufacturing with additives: improving the properties of products produced with mask stereolithography, (2014).

[78] D. Karalekas, K. Antoniou, Composite rapid prototyping: overcoming the drawback of poor mechanical properties, Journal of Materials Processing Technology 153 (2004) 526-530.

[79] Y. Lu, Mechanical properties of random discontinuous fiber composites manufactured from wetlay process, Virginia Polytechnic Institute and State University, 2002.

[80] A. Butscher, M. Bohner, S. Hofmann, L. Gauckler, R. Muller, Structural and material approaches to bone tissue engineering in powder-based three-dimensional printing, Acta Biomaterialia 7 (2011).

[81] S.A. Uhland, R.K. Holman, S. Morissette, M.J. Cima, E.M. Sachs, Strength of green ceramics with low binder content, Journal of the American Ceramic Society 84(12) (2001).

[82] J. Czyżewski, P. Burzyński, K. Gaweł, J. Meisner, Rapid prototyping of electrically conductive components using 3D printing technology, Journal of Materials Processing Technology 209(12) (2009) 5281-5285.

[83] S. Kumar, J.P. Kruth, Composites by rapid prototyping technology, Materials \& Design 31(2) (2010) 850-856.

[84] J. Torres, J. Cotelo, J. Karl, A. Gordon, Mechanical Property Optimization of FDM PLA in Shear with Multiple Objectives, JOM 67(5) (2015) 1183-1193.

[85] S.Y. Fu, B. Lauke, E. Mäder, C.Y. Yue, X. Hu, Tensile properties of short-glass-fiber- and shortcarbon-fiber-reinforced polypropylene composites, Composites Part A: Applied Science and Manufacturing 31(10) (2000) 1117-1125.

[86] markforged FAQs, 2014. markforged.com.

[87] M. Namiki, M. Ueda, A. Todoroki, Y. Hirano, R. Matsuzaki, 3D printing of continuous fiber reinforced plastic, SAMPE Tech Seattle 2014 Conference, June 2, 2014 - June 5, 2014, Soc. for the Advancement of Material and Process Engineering, 800 Convention Place, Seattle, WA 981012350, United states, 2014, p. SAMPE's Carolinas Chapter; SAMPE's Seattle Chapter. 
[88] F. Van Der Klift, Y. Koga, A. Todoroki, M. Ueda, Y. Hirano, R. Matsuzaki, 3D printing of continuous carbon fibre reinforced thermo-plastic (CFRTP) tensile test specimens, Open Journal of Composite Materials 6(01) (2015) 18.

[89] R. Matsuzaki, M. Ueda, M. Namiki, T.-K. Jeong, H. Asahara, K. Horiguchi, T. Nakamura, A. Todoroki, Y. Hirano, Three-dimensional printing of continuous-fiber composites by in-nozzle impregnation, Scientific Reports 6 (2016) 23058.

[90] A.R. Torrado, C.M. Shemelya, J.D. English, Y. Lin, R.B. Wicker, D.A. Roberson, Characterizing the effect of additives to $A B S$ on the mechanical property anisotropy of specimens fabricated by material extrusion 3D printing, Additive Manufacturing 6 (2015) 16-29.

[91] K. Tyler, Method and apparatus for continuous composite three-dimensional printing, Google Patents, USA, 2014, p. 11.

[92] J.M. Gardner, G. Sauti, J.-W. Kim, R.J. Cano, R.A. Wincheski, C.J. Stelter, B.W. Grimsley, D.C. Working, E.J. Siochi, Additive Manufacturing of Multifunctional Components Using High Density Carbon Nanotube Yarn Filaments, (2016).

[93] W. Zhong, F. Li, Z. Zhang, L. Song, Z. Li, Short fiber reinforced composites for fused deposition modeling, Materials Science and Engineering: A 301(2) (2001) 125130.

[94] M.L. Shofner, F.J. Rodríguez-Macías, R. Vaidyanathan, E.V. Barrera, Single wall nanotube and vapor grown carbon fiber reinforced polymers processed by extrusion freeform fabrication, Composites Part A: Applied Science and Manufacturing 34(12) (2003) 1207-1217.

[95] R.S. Crockett, J. O'Kelly, P.D. Calvert, B.D. Fabes, K. Stuffle, P. Creegan, R. Hoffman, Predicting and controlling resolution and surface finish of ceramic objects produced by stereodeposition processes, Proceedings Solid Freeform Fabrication Symposium, University of Texas at Austin (1995) 17-24.

[96] F.D. Ning, W.L. Cong, J.J. Qiu, J.H. Wei, S.R. Wang, Additive Manufacturing of Carbon Fiber Reinforced Thermoplastic Composites using Fused Deposition Modeling, Composites Part B: Engineering (0).

[97] F. Ning, W. Cong, J. Qiu, J. Wei, S. Wang, Additive manufacturing of carbon fiber reinforced thermoplastic composites using fused deposition modeling, Composites Part B: Engineering 80 (2015) 369-378.

[98] F. Ning, W. Cong, Y. Hu, H. Wang, Additive manufacturing of carbon fiber-reinforced plastic composites using fused deposition modeling: Effects of process parameters on tensile properties, Journal of Composite Materials (2016).

[99] Z. Quan, Z. Larimore, A. Wu, J. Yu, X. Qin, M. Mirotznik, J. Suhr, J.-H. Byun, Y. Oh, T.-W. Chou, Microstructural design and additive manufacturing and characterization of 3D orthogonal short carbon fiber/acrylonitrile-butadiene-styrene preform and composite, Composites Science and Technology 126 (2016) 139-148.

[100] Z. Quan, A. Wu, M. Keefe, X. Qin, J. Yu, J. Suhr, J.-H. Byun, B.-S. Kim, T.-W. Chou, Additive manufacturing of multi-directional preforms for composites: opportunities and challenges, Materials Today 18(9) (2015) 503-512.

[101] P. Calvert, T.L. Lin, H. Martin, Extrusion freeform fabrication of chopped-fibre reinforced composites, High Performance Polymers (1997).

[102] J. Peng, T.L. Lin, P. Calvert, Orientation effects in freeformed short-fiber composites, Composites Part A: Applied Science and Manufacturing 30(2) (1999) 133-138.

[103] P. Calvert, G. George, L. Rintoul, Monitoring of Cure and Water Uptake in a Freeformed Epoxy Resin by an Embedded Optical Fiber, Chemistry of Materials 8(6) (1996) 1298-1301.

[104] L.R. Holmes, J.C. Riddick, Research Summary of an Additive Manufacturing Technology for the Fabrication of 3D Composites with Tailored Internal Structure, JOM 66(2) (2014) 270-274. 
[105] R.R. Collino, T.R. Ray, R.C. Fleming, J.D. Cornell, B.G. Compton, M.R. Begley, Deposition of ordered two-phase materials using microfluidic print nozzles with acoustic focusing, Extreme Mechanics Letters.

[106] D. Kokkinis, M. Schaffner, A.R. Studart, Multimaterial magnetically assisted 3D printing of composite materials, Nat Commun 6 (2015).

[107] D. Klosterman, R. Chartoff, N. Osborne, G. Graves, Composites via Laminated Object Manufacturing (LaM), Seventh International Conference on Rapid Prototyping, San Francisco, 1997.

[108] D. Klosterman, R. Chartoff, G. Graves, N. Osborne, B. Priore, Interfacial characteristics of composites fabricated by laminated object manufacturing, Composites Part A: Applied Science and Manufacturing 29(9) (1998) 1165-1174.

[109] D. Klosterman, R. Chartoff, N. Osborne, G. Graves, A. Lightman, G. Han, A. Bezeredi, S. Rodrigues, Development of a curved layer LOM process for monolithic ceramics and ceramic matrix composites, Rapid Prototyping Journal 5(2) (1999) 61-71.

[110] C.R. Brooks, A. Choudhury, Failure analysis of engineering materials, McGraw-Hill New York2002.

[111] A. Simchi, H. Pohl, Direct laser sintering of iron-graphite powder mixture, Materials Science and Engineering: A 383(2) (2004) 191-200.

[112] K.K.B. Hon, T.J. Gill, Selective laser sintering of SiC/polyamide composites, CIRP AnnalsManufacturing Technology 52(1) (2003) 173-176.

[113] J.P. Kruth, P. Mercelis, J.V. Vaerenbergh, L. Froyen, M. Rombouts, Binding mechanisms in selective laser sintering and selective laser melting, Rapid Prototyping Journal 11(1) (2005) 26-36.

[114] D. systems. http://www.3dsystems.com/.

[115] C. Yan, L. Hao, L. Xu, Y. Shi, Preparation, characterisation and processing of carbon fibre/polyamide-12 composites for selective laser sintering, Composites Science and Technology 71(16) (2011) 1834-1841.

[116] J.J. Beaman, J.W. Barlow, D.L. Bourell, R.H. Crawford, H.L. Marcus, K.P. McAlea, Solid freeform fabrication: a new direction in manufacturing, Kluwer Academic Publishers, Norwell, MA 2061 (1997) 25-49. 